
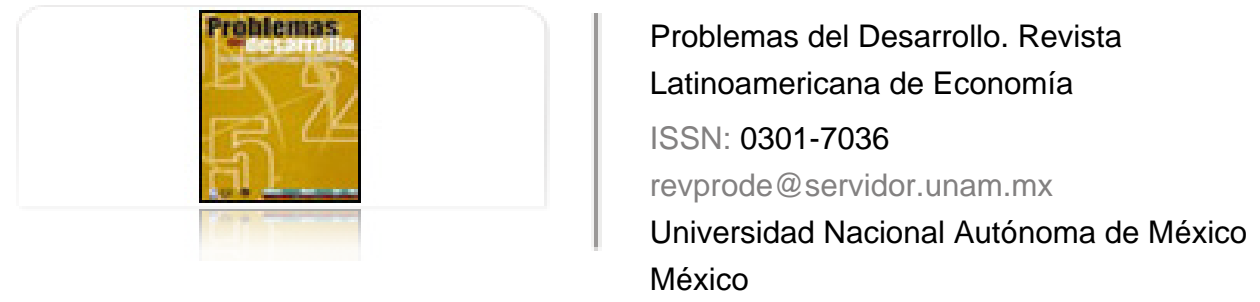

Soria, Víctor M.

EI MERCOSUR en la estrategia de desarrollo económico de Brasil

Problemas del Desarrollo. Revista Latinoamericana de Economía, vol. 34, núm. 133, 2003, pp. 49-78

Universidad Nacional Autónoma de México

Distrito Federal, México

Disponible en: http://www.redalyc.org/articulo.oa?id=11825949010

Cómo citar el artículo

- Número completo

- Más información del artículo

Página de la revista en redalyc.org

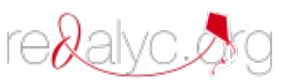

Sistema de Información Científica

Red de Revistas Científicas de América Latina, el Caribe, España y Portugal Proyecto académico sin fines de lucro, desarrollado bajo la iniciativa de acceso abierto 


\title{
EL MERCOSUR EN LA ESTRATEGIA DE DESARROLLO ECONÓMICO DE BRASIL *
}

\section{Víctor M. Soria**}

Fecha de recepción: 15 de agosto de 2003. Fecha de autorización: 28 de octubre de 2003.

\section{Resumen}

En este trabajo se analiza el cambio en la estrategia de desarrollo económico de Brasil a partir de 1990, al abrazar un modelo de crecimiento por exportaciones, reforzado en 1991 con la creación, junto con tres países vecinos, del MERCOSUR. El comercio intra MERCOSUR se duplicó entre 1993 y 1997, lo que contribuyó al crecimiento del PIB de los países miembros. Sin embargo, la creciente falta de voluntad política para consolidar el MERCOSUR vis à vis al intercambio con la Unión Europea y Estados Unidos, aunado a la fragilidad macroeconómica proveniente del modelo de estabilización que desembocó en crisis a partir de 1999, llevaron al desplome del intercambio intra MERCOSUR que puso en peligro su existencia. Las negociaciones del ALCA han llevado a los miembros del MERCOSUR a tomar conciencia de su identidad unitaria, de su interdependencia y de la necesidad de su conservación y reforzamiento.

Palabras clave: desarrollo económico, integración regional, modelo de estabilización neoliberal, comercio exterior.

\begin{abstract}
This paper analyzes the change in Brazil's strategy for economic development beginning in 1990, when it embraced an export-based growth model, strengthened with the creation of MERCOSUR in 1991 together with three neighboring countries. Intra-MERCOSUR trade doubled between 1993 and 1997, which contributed to growth in the GDPs of member countries. Nevertheless, the increasing lack of political will to consolidate MERCOSUR vis à vis trade with the European Union and the United States, added to macroeconomic fragility from the stabilization model that led to crisis beginning in 1999, in turn led to the collapse of intraMERCOSUR trade, thus endangering its existence. FTAA negotiations have caused MERCOSUR members to become aware of their shared identity, their interdependence and the need for the conservation and strengthening of MERCOSUR.
\end{abstract}

Key words: economic development, regional integration, neoliberal stabilization model, foreign trade.

\footnotetext{
Agradezco las recomendaciones de tres dictaminadores las cuales han contribuido a mejorar esta comunicación. También agradezco la colaboración de Braulio A. Méndes, asistente del INTAM, su apoyo para la información estadística y la elaboración de las gráficas de este trabajo.

** Departamento de Economía, UAM Iztapalapa y miembro del iNTAM.
} 


\section{Résumé}

Dans ces travaux, se trouvent analysé le changement dans la stratégie de développement économique du Brésil à partir de 1990, en faisant le tour d'un modèle de croissance pour les exportations, renforcé par la création en 1991 du MERCOSUR conjointement avec trois pays voisins. Le commerce intra-MERCOSUR a doublé entre 1993 et 1997, ce qui a contribué à la croissance du PIB des pays membres. Cependant, le manque croissant de volonté politique afin de consolider le MERCOSUR concernant l'échange avec l'Union Européenne et les Etats-Unis, ajouté à la fragilité macro-économique provenant du modèle de stabilisation ayant débouché sur une crise à partir de 1999, ont mené à l'écroulement de l'échange intra-MERCOSUR qui a mis en danger sa propre existence. Les négociations de l'ALCA ont mené les membres du MERCOSUR à prendre conscience de leur identité unitaire, de leur inter-dépendance et du besoin de leur conservation et leur renforcement.

Mots-cléfs: développement économique, intégration régionale, modèle de stabilisation néolibérale, commerce extérieur.

\section{Resumo}

Neste trabalho analisa-se a mudança na estratégia de desenvolvimento econômico no Brasil a partir de 1990, quando abraçou um modelo de crescimento por exportações, reforçado com a criação, em 1991, do MERCOSUL, junto com três países vizinhos. O comércio intra MERCOSUL duplicou-se entre 1993 e 1997, contribuindo com o crescimento do PIB dos países membros. Entretanto, a crescente falta de vontade política para consolidar o MERCOSUL em face do intercambio com a União Européia e os Estados Unidos, unida à fragilidade macro-econômica proveniente do modelo de estabilização que desembocou em crise a partir de 1999, levaram à derrubada do intercâmbio intra MERCOSUL, colocando em perigo a sua existência. As negociações da ALCA levaram os membros do MERCOSUL a tomar consciência da sua identidade unitária, da sua interdependência e da necessidade da sua conservação e fortalecimento.

Palavras chave: desenvolvimento econômico, integração regional, modelo de estabilização neo-liberal, comércio exterior. 


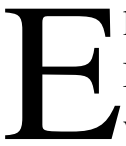

1 propósito de este trabajo es analizar las estrategias de desarrollo económico de Brasil y cómo se vincula la nueva estrategia de este país, surgida en los años noventa, con el Mercado Común del Sur (MERCosur). También se examinan las causas de la crisis de este esquema de integración al final de los años noventa, así como sus divergencias con el proceso de negociación del Área de Libre Comercio de las Américas (ALCA), en las que Brasil ha desempeñado un papel protagónico.

El desarrollo económico de Brasil a partir de 1930 ha estado fincado en dos modelos, uno el de industrialización por sustitución de importaciones, vigente hasta finales de 1980 y otro de crecimiento hacia afuera por exportaciones, cuyo embrión comienza con el gobierno de Collor de Mello (1990-1992) y que tendió a afianzarse durante los dos periodos de gobierno de Fernando Enrique Cardoso (F.H.C., 1994-2002), y continúa sin cambios en el nuevo gobierno de Luiz Inácio Lula da Silva, por lo que aún está lejos de consolidarse como alternativa al modelo anterior.

Los regímenes militares brasileños que arribaron al poder en 1964, en el cual permanecieron hasta la primera mitad de la década de los ochenta, trataron de construir un modelo de acumulación que se acercó a lo que Valenzuela (1990) denominó "secundarioexportador", ${ }^{1}$ es decir, fase avanzada de la sustitución de importaciones con la protección de la competencia externa ligeramente declinante, y cuya producción se dedicó mayormente al consumo de las clases medias y altas, a través de una estructura de distribución del ingreso altamente desigual. Pero dicho modelo encontró sus límites tanto por ese sesgo excluyente como por la incapacidad para construir un sector de bienes de producción con capacidad de innovación suficiente para ser menos dependiente del sistema productivo.

Las grandes transformaciones propiciadas por el proceso de globalización económica en los años ochenta repercutieron tanto en Brasil como en América Latina, a través del retiro del financiamiento externo por parte de los países desarrollados y la banca internacional que, conjuntado con las crecientes dificultades del modelo de crecimiento por sustitución de importaciones, provocaron la crisis de la llamada década perdida, signada por la crisis de la deuda externa, grandes devaluaciones de las monedas locales acompañadas de drásticos ajustes en las economías domésticas, la transferencia de importantes excedentes al extranjero y un creciente empobrecimiento de la clase trabajadora.

\footnotetext{
Los principales rasgos del patrón secundario exportador, también denominado por Valenzuela (1990:158) "pragmático desarrollista", tiene como características el activismo estatal; el impulso a la industrialización pesada; la apertura externa gradual, selectiva y con especialización internacional dinámica; preservación de las esferas de inversión al capital nacional, así como con fortalecimiento del capital industrial y regulación del capital de préstamo.
} 
En 1990, la liberalización comercial y financiera arriba a América Latina, acompañada del modelo de estabilización con "desinflación competitiva"2 que somete a las economías de la región a un crónico desequilibrio del sector externo y a déficit fiscales e, inexorablemente, a crisis financieras como la de México en 1994-1995 y la de Brasil en 1998-1999. La década de los noventa se caracteriza también por el incremento del intercambio económico entre Estados Unidos y los países de América Latina, así como por la convergencia de los gobiernos de la región con la política del Washington Consensus, aunada a una racionalidad ex post de acuerdo con la cual el crecimiento podría ser apoyado por las exportaciones y que requería el desmantelamiento de la protección comercial y la promoción de un modelo abierto de inserción en la economía mundial (Bouzas 1996: 91). En este clima de cambio de paradigma de la política de intercambio externo en América Latina se observa una ola de liberalización comercial unilateral en los países de la región, ${ }^{3}$ además de una proliferación de acuerdos de comercio bilaterales entre los países latinoamericanos y entre éstos y Estados Unidos, y entran en vigor dos importantes esquemas de integración: el MERCOSUR en 1991 y el TLCAN en 1994. Al mismo tiempo se inician pláticas para un acuerdo hemisférico, el Área de Libre Comercio de las Américas (ALCA) que se espera entre en vigor en el año 2005.

El impasse en el que se encuentra el MERCOSUR, como se analiza en el texto, no sólo obedece a la crisis de las economías argentina y brasileña propiciadas por el modelo neoliberal y su vulnerabilidad ante shocks externos, sino principalmente a la falta de compromiso político con los objetivos comunes, así como a los vacíos de gestión generados por la insuficiente institucionalización del esquema de integración. El proceso de negociación del ALCA, liderado por Estados Unidos, también ha influido en el funcionamiento del MERCOSUR y lo ha contaminado desde un principio con la semilla del libre comercio.

El presente trabajo está organizado en seis secciones: en la primera se expone una síntesis de las estrategias de desarrollo económico seguidas por Brasil y su participación en esquemas de cooperación económica con países de la región que anteceden al MERCOSUR; en la segunda sección se analiza la evolución de éste en su etapa de crecimiento y éxito hasta 1998, seguida del examen, en la tercera parte, de la crisis de la economía brasileña y su influencia en la declinación del comercio intra MERCOSUR; en la cuarta sección se analizan las causas fundamentales de la crisis del MERCOSUR, y en la quinta se examinan las

El adjetivo competitiva se utiliza para convencer de que dicha política llevará a la reactivación de la producción, al aumento de la productividad del trabajo y a la disminución de la pobreza. La justificación afirma que una política de sobrevaluación del tipo de cambio tiene efectos similares a los de un progreso técnico capital saving, cuando las importaciones que promueve están concentradas en bienes intermedios y bienes de capital. Pero como esta política va acompañada de liberalización económica y altas tasas de interés real, tiene efectos macroeconómicos destructivos y un elevado costo social (Salama, 1999:27).

3 Las reformas comerciales con orientación liberalizadora se generalizaron en América Latina en la década de los noventa. Ocho países, entre los que se incluyen Argentina, Brasil y México introdujeron reformas que pueden catalogarse como drásticas y abruptas. En siete de los ocho países "la liberalización de las importaciones se llevó a cabo en un periodo de dos o tres años (1989 1990 a 1992 1993)" (Agosin y Ffrench Davis, 1993:45). 
divergencias de Brasil y el MERCOSUR con el proceso de construcción del ALCA. Finalmente en la sexta parte se vierten algunas reflexiones finales a manera de conclusión.

\section{La estrategia desarrollista brasileña y el cambio hacia un desarrollo neoliberal hacia afuera}

Entre la época en que se presenta la crisis del capitalismo mundial a mediados de 1970 y la ola de transformaciones económicas y políticas en los años ochenta — traídas por la globalización económica一, se inicia en Brasil un largo proceso de transición política hacia la democratización, conjuntamente con agudos problemas económicos y sociales a raíz de la crisis de principios de los ochenta y los ajustes económicos que le siguieron. La refuncionalización del modelo nacionalista con endeudamiento, que trataron de llevar a cabo los regímenes militares autoritarios a partir del golpe en 1964, finalmente desembocó en el agotamiento de dicho modelo y en la crisis del Estado nacional-desarrollista, viéndose obligados a ceder el poder a la sociedad civil en 1985.

Después de acceder a una etapa de crecimiento calificada como el milagro económico brasileño entre 1967 y 1972, el agotamiento del modelo sustitutivo de importaciones dio paso, hacia 1973, a una estrategia voluntarista denominada marcha forzada a la industrialización entre 1974 y 1979, la cual puso el énfasis en la sustitución de importaciones de bienes de capital y bienes intermedios, así como en la exportación de manufacturas. A pesar de los progresos logrados, el problema del servicio de la deuda externa empezó a catalizar las contradicciones del régimen de acumulación "desde dentro". Al agotarse el modelo de crecimiento con endeudamiento, sobrevino una gran recesión entre finales de 1980 y el segundo semestre de 1984. En 1985 hubo una tendencia a la recuperación, con base en el dinamismo de las exportaciones, y se llegó, en 1986, a un cierto auge económico, pero en 1987 y 1988 se presentó otra tendencia a la baja, seguida por un nuevo pico en 1989 y a partir de ahí se inició una creciente recesión. El periodo estuvo marcado, pues, por una hiperinflación, con periodos cortos de estabilidad en la segunda mitad de los ochenta. La estabilidad se trató de alcanzar a través de diversos planes económicos: en 1985 se instrumentó el Plan Cruzado con ajuste recesivo; después vinieron los planes de ajuste heterodoxo, en los cuales se aplicó en 1987 el Plan Bresser y en 1989 el Plan Verão; posteriormente, en 1990, el Plan Collor vuelve a un ajuste de tipo recesivo ( $c f$. Soria, 1995).

En vista del shock monetarista instrumentado por el gobiernode James Carter en 1979, durante la gestión de Volcker en la Reserva Federal estadounidense, cesó el financiamiento externo y cayeron tanto los préstamos privados como los públicos, dando lugar a una enorme transferencia líquida de recursos hacia el exterior provocada en gran parte por el servicio de la deuda externa. Además, se dio una caída de la inversión extranjera directa, por lo que la década de los ochenta se convirtió, más bien, en un periodo de desinversión. No obstante, a pesar de que la economía brasileña pasó por un estancamiento económico 
y no logró la estabilidad de precios, ni pudo definir un nuevo modelo de desarrollo, por el lado político la sociedad empezó a mostrar el comienzo de un florecimiento democrático.

Las profundas transformaciones de la economía internacional y el advenimiento de la época neoliberal con su política de austeridad económica y ajustes draconianos, contribuyeron, en el caso de Brasil, a distraer su política económica de la trayectoria desarrollista, tratando de adaptarse a las nuevas condiciones externas. Por una parte, el servicio de la deuda obliga a obtener superávit en la balanza comercial para cubrirlo, y las empresas paraestatales son apartadas de su propia dinámica y sometidas a los lineamientos del ajuste. Por otra parte, a pesar de la senda de agotamiento por la que atravesaba la sustitución de importaciones, el modelo nacional-desarrollista se trató de consolidar jurídicamente en la Constitución de 1988, ${ }^{4}$ mientras las empresas transnacionales empujaban el proceso de globalización a nivel mundial (Sallum, 1997:13).

Sin embargo, el plasmar en la nueva Constitución las líneas generales del viejo modelo desarrollista de poco sirvió, ya que a partir del gobierno de Collor de Mello (marzo de 1990 a septiembre de 1992) se instrumentó una importante ruptura con ese modelo, y surgió el embrión de una nueva estrategia de desarrollo hacia afuera, que aprovecha tanto el clima internacional de liberalización comercial como la trayectoria de integración regional con Argentina iniciada desde 1985, que cristaliza en 1991 con la constitución del MERCOSUR. Empero, la administración de Collor de Mello no tuvo ni la decisión suficiente ni el tiempo para consolidar el embrión del desarrollo neoliberal, el cual fue rediseñando posteriormente la administración de Cardoso.

El gobierno de Collor de Mello desistió de construir una estructura industrial integrada y protegida de la competencia externa por el Estado (Sallum, 1997:14); más bien lo que perseguía era preservar sólo aquellas ramas que se mostraban capaces de lograr una competitividad a nivel internacional después de un periodo de adaptación. Es por ello que a partir de 1990 se implementó un programa de liberalización comercial, que logró bajar el arancel máximo de $105 \%$ a 35\% en dos años, así para fines de 1992 el arancel promedio había descendido a 21\% (Agosin y Ffrench Davis, 1993:44). Simultáneamente, el gobierno de Collor de Mello implementó un programa de desregulación económica y privatización de empresas paraestatales con la finalidad de recuperar el nivel de las finanzas públicas y reducir al mínimo su papel impulsor de la industria brasileña (Sallum, 1997:14).

No obstante, el Plan Collor fracasó en cuanto a conseguir la estabilización de la economía. La recuperación económica se inicia en 1993, pero la inflación se incrementa y en 1994 el Plan Real, implementado en el último año del presidente Itamar Franco, logra

Sin embargo, no todos los capítulos de la nueva Constitución de 1988 mostraban un anacronismo, ya que sin duda presentó avances significativos en cuanto al patrón de protección social vigente. Se ampliaron los derechos sociales, la universalización del acceso y la expansión de la cobertura; se distendió el vínculo contributivo co mo principal estructurante del sistema, se definieron los beneficios sociales mínimos, así como un mayor com promiso del Estado y de la sociedad en el financiamiento del sistema de protección social (Draibe, 1992:62 63). 
reducirla a un nivel bajo. Este plan buscaba la estabilización rápida de los precios, para lo cual se establecieron las siguientes medidas de acuerdo con un compendio realizado por Brasilio Sallum Jr. (1999:38):

a) mantener un tipo de cambio sobrevaluado frente al dólar para bajar la tasa de inflación y el abaratamiento de las importaciones; $b$ ) abaratamiento de divisas y ampliación de la apertura comercial para la renovación rápida del parque industrial y mayor competitividad de exportaciones; $c$ ) política de intereses altos para atraer el capital extranjero, mantener reservas cambiarias elevadas, financiar el déficit externo y reducir el nivel de actividad económica interna para evitar el crecimiento de las importaciones; $d$ ) realizar un ajuste fiscal progresivo de mediano plazo basado en la recuperación de la carga tributaria, en el control progresivo del gasto público y en reformas estructurales (seguridad social, tributaria y administrativa), para equilibrar definitivamente las cuentas públicas; e) no ofrecer estímulos directos a las actividades económicas, debiendo concentrarse el Estado en la preservación de la concurrencia a través de la regulación y fiscalización de las actividades productivas.

A partir de la recuperación económica en 1993 el nivel medio de productividad en el sector industrial sube, lo cual se refleja en el aumento salarial y en otros beneficios, lo que aumentó la demanda de servicio y generó oportunidad de empleo para los trabajadores por cuenta propia y los de servicio doméstico, además de alentar un gran número de pequeños negocios que amplían el trabajo familiar sin remuneración y el empleo en los sectores informales.

El Plan Real permitió reforzar la recuperación económica iniciada en 1993, además de bajar la inflación y elevar el ingreso per cápita, hizo posible el aumento del consumo y la demanda efectiva. Es así, que los grupos más pobres de la población impulsaron el consumo de bienes básicos y las capas medias el consumo de bienes durables, apoyadas estas últimas en créditos al consumo, si bien con tasas altas de interés, pero con amplios plazos de pago. Se inicia un proceso de baja en la inflación y una lenta recuperación de la inversión privada, lo cual promovió el crecimiento económico y el empleo, aunque la creación de empleos asalariados formales fue pequeña (Cacciamali, 1998:2).

La inflexión neoliberal que se dio durante el gobierno de Collor de Mello y su estrategia embrionaria de desarrollo fue conservada por los gobiernos posteriores, en cuanto a la apertura comercial y las privatizaciones, aunque con algunos titubeos. En la administración de Cardoso se comienzan a profundizar algunas "virtualidades desindustrializantes y desnacionalizantes" del programa liberal de integración (Sallum, 1997:16).

Si bien el Plan Real, a través de la valoración de la moneda nacional, controló la inflación y aumentó la renta disponible y la demanda de las capas pobres de la población, presionó a la vez las cuentas externas fragilizando los equilibrios macroeconómicos. El gobierno, entonces, modificó su política cambiaria flexibilizándola un poco hacia una leve desvaloración del real, aumentó las tasas de interés y las tarifas de importación que 
afectaron a 106 productos, así como medidas de protección sectorial, las cuales se orientaron hacia una reafirmación industrial. Como expresa Brasilio Sallum (ibid.:12) el gobierno de Cardoso implantó una política "dual": por un lado la estabilización de precios con un equilibrio de largo plazo para las cuentas externas y, por otro, políticas de protección y estímulo para segmentos económicos con capacidad de presión política, para compensar los efectos negativos de la política macroeconómica.

Los resultados del Plan Real, junto con el excelente desempeño de las exportaciones brasileñas al interior del MERCOSUR entre 1994 y 1998 (que se analizan más adelante), le dieron al gobierno de Cardoso los grados de libertad necesarios para realizar algunas reformas estructurales de carácter neoliberal. Sin embargo, la naturaleza de las reformas y la política económica diseñada sobre un tipo de cambio sobrevaluado, elevadas tasas de interés y la cobertura de los desequilibrios externo y fiscal con capital extranjero, mostraron sus límites hacia finales de 1998 y sentaron las condiciones para la crisis de 1999.

Antes de pasar al análisis del MERCosur, veamos, brevemente, el interés de Brasil en la integración económica con sus vecinos más cercanos, como antecedente a la constitución de dicho esquema de integración. La vecindad geográfica y el crecimiento natural del intercambio de Brasil con sus vecinos, así como la necesidad de empujar la industrialización y relanzar el crecimiento, lo llevan a buscar la cooperación, la cual tuvo que remontar las dificultades de la competencia política y económica con Argentina, en vista de la búsqueda de hegemonía regional por los dos países. Así, un acercamiento fructífero de Brasil con Argentina y Paraguay se realizó en 1979, en términos del Tratado para compatibilizar las cotas de las represas hidroeléctricas de Itaipú y Corpus Cristi. Posteriormente Argentina y Brasil firmaron un convenio de cooperación nuclear en 1980. El marco inicial del proceso de integración regional, propiamente se estableció en noviembre de 1985 con la Declaración de Iguazú entre Argentina y Brasil, que expresaba la voluntad de acelerar la integración bilateral mediante la creación de una Comisión Mixta de Alto Nivel (CEPAL 2002:19).

En julio de 1986 los presidentes Alfonsín de Argentina y Sarney de Brasil firmaron en Buenos Aires el Acta para la Integración Argentino-Brasileña, en virtud de la cual se estableció el Programa de Integración y Cooperación Económica entre Argentina y Brasil, en cuya primera etapa se aprobaron 12 protocolos sectoriales, los que posteriormente aumentaron a 24. Entre los protocolos sobresalen los de las industrias de bienes de capital, la automotriz, la siderúrgica y la de alimentos (Lerman, 2002:102).

En 1988 Argentina y Brasil, a pesar de las dificultades económicas y la pérdida de crecimiento por las que atravesaban, firmaron en Buenos Aires el Tratado de Integración, Cooperación y Desarrollo, cuya finalidad fue la de crear un mercado común entre los dos países, para lo cual fijaron un plazo de diez años para eliminar todas las barreras arancelarias y no arancelarias recíprocas (ibid.). 
Hacia 1990 el nuevo gobierno de Collor de Mello efectuó un drástico cambio en la política de desarrollo económico, y se inclinó hacia la apertura de mercados y la demolición del modelo de sustitución de importaciones, por lo que convergió con orientaciones similares del gobierno de Menem; ambos firmaron en 1990 el Acta de Buenos Aires, mediante la cual adelantaron para diciembre de 1994 (en lugar del plazo de diez años), la constitución del mercado común. El Acta enfatizó el uso de mecanismos de corte liberalizante fundados en rebajas arancelarias, con reducidas listas de excepciones y estrictos calendarios, así mismo acentúo la reducción del grado de intervención gubernamental en los acuerdos sectoriales (ibid::103). De aquí a la constitución del MERCosur quedaba un corto camino.

\section{La evolución del MERCOSUR}

En los orígenes del MERCOSUR convergió, especialmente, el interés de las dos economías mayores de la región, Argentina y Brasil, que las llevaron a acercamientos sucesivos que sentaron las bases de un acuerdo de integración de largo aliento, al que poco después se sumaron otros dos países. En el ánimo de cooperación económica de los miembros del nuevo esquema influyeron varios elementos: por una parte el agotamiento de la industrialización sustitutiva de importaciones, así como la crisis de los años ochenta y su impacto económico y social que puso de manifiesto el peligro de depender del crédito de los países centrales. Se supuso que la integración podría ayudar a renegociar las deudas mediante la creación de un frente unido de deudores, pero tal cosa nunca llegó a realizarse. Por otra parte, en esos años, los cuatro países que ahora forman el MERCOSUR, conocieron una transición democrática después de un largo periodo de dictadura militar, lo que lleva a afirmar que las condiciones políticas fueron uno de los determinantes principales de su creación. El Tratado de Asunción, firmado el 26 de marzo de 1991 en Paraguay, estipula que la democracia es una condición fundamental para pertenecer a éste, lo que obligó a todos sus signatarios a defenderla (Schvarzer, 1999:82).

El MERCOSUR constituye el acuerdo más amplio con objetivos de largo plazo y, como ya hemos visto, el antecedente más cercano fueron los acuerdos de comercio compensado entre Argentina y Brasil negociados entre 1986 y 1988. A partir de 1990 se ingresa a una segunda etapa que sobrepasa el esquema de intercambios compensados para entrar a otra de liberalización comercial más fuerte. En 1991 Paraguay y Uruguay son admitidos como nuevos socios y firman el Tratado de Asunción, para establecer un mercado común entre los cuatro países, el cual entraría en vigor al final de 1994. En diciembre de 1994 el protocolo de Ouro Preto da nacimiento a la etapa de unión aduanera, la cual entró en vigor a partir de enero de 1995. Desde la firma y posterior ratificación del Tratado en los Parlamentos, el MERCosur toma una dinámica distinta: por un lado, se amplía la participación de estados al sumarse dos nuevos miembros, y por otro lado, se establece un nuevo 
mecanismo de liberalización generalizada del comercio entre los socios. ${ }^{5}$ Los instrumentos utilizados fueron la ampliación automática de las preferencias arancelarias por periodos de seis meses (hasta alcanzar a finales de 1994 tarifas cero) y la previsión de Acuerdos Sectoriales de complementación industrial para negociar condiciones específicas. El proceso de integración evolucionó favorablemente en la primera mitad de los noventa, lo que llevó a Chile y Bolivia a sumarse al MERCosur, siendo admitidos en 1996 en calidad de países asociados.

El MERCOSUR se fijó horizontes más amplios que el TLCAN, ya que además del libre comercio de bienes y servicios prevé la libre circulación de los factores de producción, ${ }^{6}$ el establecimiento de una tarifa externa común, la coordinación de políticas en foros tanto regionales como internacionales, la coordinación de políticas macroeconómicas y sectoriales en las áreas de comercio exterior, agricultura, industria, tipo de cambio, y en las políticas fiscal, monetaria y de capitales; en servicios, aduanas, transporte, comunicaciones y otras áreas necesarias (Artículo 1o. del Tratado). Además, es muy significativo que los Acuerdos Sectoriales hayan incluido en las negociaciones, además de los representantes gubernamentales, a representantes de las empresas y los sindicatos en los sectores involucrados, lo cual le ha permitido alcanzar una mayor operatividad, como en el caso de la industria automotriz.

El arancel externo común (AEC) se estableció en diciembre de 1994 en el Protocolo de Ouro Preto, constituyéndose una Unión Aduanera (UA) imperfecta, que posteriormente se espera evolucione hacia una más acabada. El AEC entró en vigor el 1o. de enero de 1995 para $85 \%$ del universo arancelario, con un promedio de $14 \%$ y un máximo de $20 \%$ (Lerman, 2001:62). En los años siguientes, la tasa promedio ha evolucionado hacia 11\%, tasas para insumos importados entre 6 y $12 \%$, mientras que los productos de consumo final se gravan con aranceles de entre 18 y 20\% (CEPAL, 2002:20) En cuanto al restante 15\% del conjunto arancelario cada uno de los países ha establecido aranceles distintos entre 0 y $35 \%$. Las excepciones abarcan los bienes de capital, informática y telecomunicaciones. ${ }^{7}$

5 La liberalización significó un cambio en la estrategia de integración que se incorporó al mercosur, ya que se abandonaron los principios de gradualidad, flexibilidad, simetría, tratamiento preferencial frente a terceros países, la armonización progresiva de políticas y la participación, que habían sido planteados por Argentina y Brasil en el Programa de Integración, Cooperación y Desarrollo (PICE) firmado en 1986. En el MERcosur se pasó a un acuerdo de desgravación lineal y automática de 20\% anual para culminar el 31 de diciembre de 1994 con la liberalización total del comercio, concediendo un año más para Uruguay y Paraguay (Lerman, 1999).

6 Fueron admitidos tres grupos de productos como excepciones al arancel externo común: 1) bienes de capital con un arancel de 14\% a ser alcanzado en 2001 (Paraguay y Uruguay a partir de 2006); 2) bienes de informática y telecomunicaciones con un arancel de $16 \%$ a ser alcanzado en 2006 ; 3) listas de excepciones nacionales, con convergencia gradual al AEC hasta fines de 1999 (CEPAL, 2002:20). A estas excepciones hay que añadir el azúcar, único producto que no ha sido objeto de negociaciones. A fines de 2000 Argentina y Brasil acordaron que las negociaciones sobre el azúcar abarcarían todo el sector azucarero incluyendo el alcohol de azúcar. No obstante, Argentina ha prorrogado por cinco años la protección al azúcar (Lerman, 1999:21).

7 La libre circulación del capital y la fuerza de trabajo es más difícil de conseguir que la circulación de mercancías, por lo que constituye un objetivo de largo plazo. En el caso del primero, las condiciones en que se debe dar la integración se fijaron en el Protocolo para la Promoción y Protección Recíproca de las Inversiones en el 


\section{El desempeño del MerCosur en la etapa de éxito}

El MERCOSUR tuvo un excelente dinamismo hasta antes de la crisis brasileña de 1998-1999, ya que el comercio intraregional pasó de 3,639 millones de dólares en 1990 a 10,057 millones en 1993, o sea una expansión de 176\%; para 1997 el intercambio intra MERCOSUR se había incrementado a 20,583 millones de dólares, o sea un aumento de $102 \%$ (véase Cuadro 1). Hacia 1995 Argentina absorbía casi $9 \%$ de las exportaciones brasileñas, por lo que devino el segundo socio comercial de Brasil, después de Estados Unidos. Paralelamente, Brasil es el principal comprador de productos agropecuarios y manufacturados argentinos (Rodríguez, 1997:150). La ampliación del MERCosur a Chile y Bolivia le daba a este esquema en 1997 un PIB conjunto de 1,178 billones de dólares y un mercado potencial de más de 200 millones de consumidores (Secretaría del MERCosur: 1998).

En cambio las exportaciones de los países miembros del MERCosur a otros países o bloques de países tuvieron un dinamismo menor entre 1993 y 1998. Mientras las exportaciones intra MERCOSUR se doblaron, es decir, aumentaron 102\%, las exportaciones fuera de él aumentaron tan sólo 38.7\%. Las exportaciones a la Unión Europea todavía ocupaban el primer lugar en 1996, seguidas de las exportaciones a Estados Unidos, y en tercer lugar al propio MERCOSUR; para 1998 el primer sitio correspondía a éste último y el segundo y tercer lugar a la Unión Europea y a Estados Unidos, respectivamente, ${ }^{8}$ aunque a partir de la crisis brasileña de 1999 las exportaciones intra MERCOSUR empiezan a perder nivel, pasando en 1999 y 2000 a segundo lugar y al tercero en 2001 y 2002 (véase Cuadro 1).

En cuanto a las importaciones que realizó el MERCOSUR en el periodo 1993-1998, la Unión Europea ha conservado el primer lugar como proveedor, seguida, alternativamente por el abastecimiento intra MERCOSUR y el de Estados Unidos. A partir de la crisis brasileña de 1999, Estados Unidos se afirma en el segundo lugar mientras que las importaciones intra MERCOSUR pasaron al tercero (véase Cuadro 2).

Mientras el MERCOSUR incrementó el intercambio entre sus miembros entre 1990 y 1998, abría la posibilidad de una integración regional basada en un crecimiento endógeno, más que un crecimiento promovido por las exportaciones hacia Estados Unidos. La fuerte expansión de la inversión extranjera dentro del MERCOSUR reforzaba la posibilidad de una

MERCosur, así como en otro Protocolo para las Inversiones provenientes de Estados no Partes del mercosur. En cuan to al segundo ya desde el Tratado de Asunción quedaron incorporados los aspectos migratorios y laborales para regular la movilidad de la fuerza de trabajo intrazona, complementándose posteriormente con la crea ción del Grupo de Trabajo núm. 10, encargado de los asuntos laborales, empleo y seguridad social, el cual avanzó en la elaboración de una Carta Social para proteger los derechos de los trabajadores, la cual que dio lugar a la adopción definitiva de la Declaración Sociolaboral del MERCosur por la Cumbre Presidencial celebrada en diciembre de 1998. También desde 1997 se aprobó el Protocolo de Montevideo sobre el Comercio de Ser vicios del MERCOSUR, que contiene disposiciones específicas sectoriales con relación a movimientos de personas físicas proveedoras de servicios, servicios financieros y servicios de transporte terrestre, aéreo y por agua.

8 Las exportaciones al resto del mundo presentan una cantidad superior a las exportaciones a Estados Unidos, pero incluyen un gran número de países que individualmente reciben cantidades menores de exportación, razón por la que el resto del mundo no se incluye como bloque en la comparación anterior. 
Cuadro 1

Exportaciones del MERCOSUR 1993-2002

(millones de dólares)

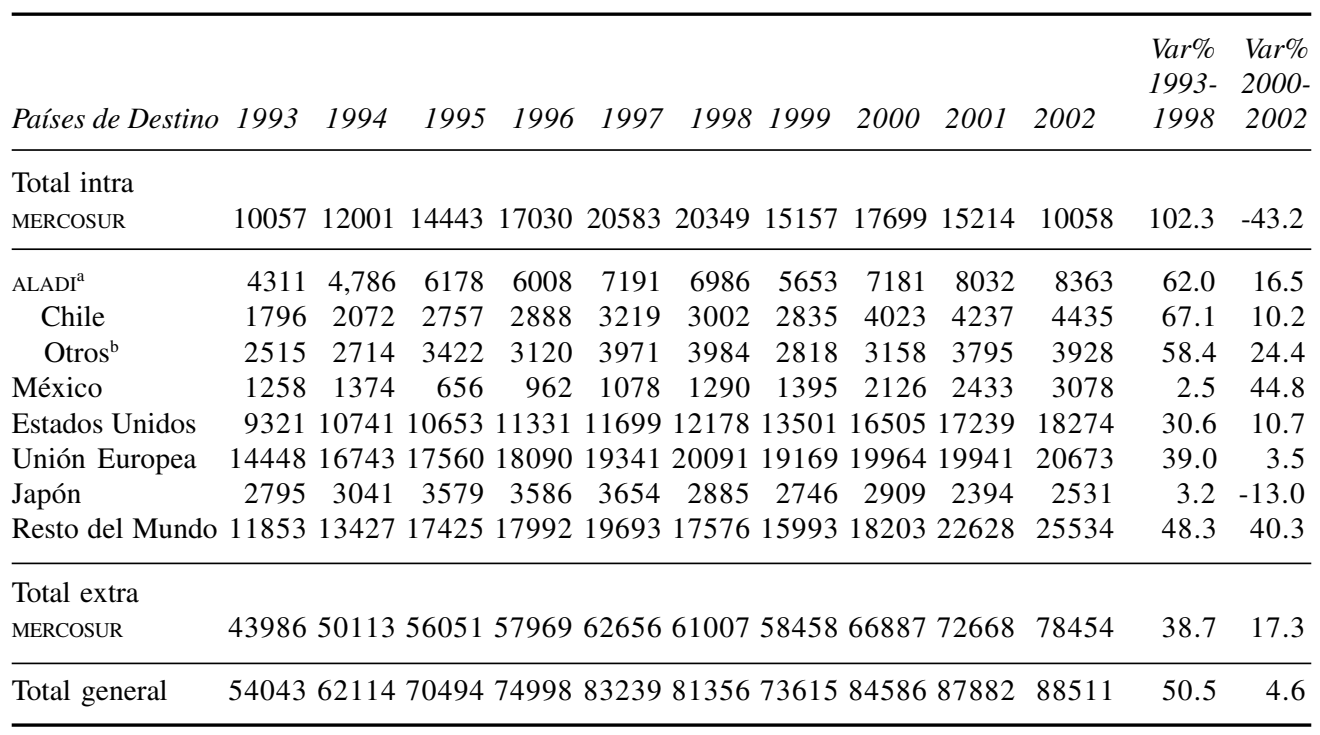

a Excluye al MERCosur y a México

b Incluye Bolivia, Colombia, Cuba, Ecuador, Perú y Venezuela.

Fuente: CEI con base en INDEC, SECEX, Secretaría Administrativa del MERCOSUR y Banco Central de Uruguay.

Cuadro 2

Importaciones del MERCOSUR 1993-2002

(millones de dólares)

\begin{tabular}{|c|c|c|c|c|c|c|c|c|c|c|c|c|}
\hline Países de Destino & 1993 & 1994 & 1995 & 1996 & 1997 & 1998 & 1999 & 2000 & 2001 & 2002 & $\begin{array}{c}\text { Var\% } \\
1993- \\
1998\end{array}$ & $\begin{array}{l}\text { Var\% } \\
2000 \\
2002\end{array}$ \\
\hline \multicolumn{13}{|l|}{ Total intra } \\
\hline MERCOSUR & 9086 & 11710 & 13995 & 17197 & 20491 & 20476 & 15426 & 17576 & 15331 & 10344 & 125.3 & -41.1 \\
\hline ALADI $^{\mathrm{a}}$ & 1913 & 2470 & 3376 & 3603 & 3798 & 3266 & 3271 & 4231 & 3339 & 2429 & 70.7 & -42.6 \\
\hline Chile & 988 & 1255 & 1733 & 1599 & 1782 & 1604 & 1413 & 1675 & 1460 & 870 & 62.3 & -48.1 \\
\hline Otros $^{b}$ & 925 & 1216 & 1642 & 2004 & 2016 & 1662 & 1859 & 2556 & 1879 & 1558 & 79.7 & -39.0 \\
\hline México & 617 & 641 & 1254 & 1569 & 1857 & 1644 & 1158 & 1394 & 1188 & 762 & 166.4 & -45.3 \\
\hline Estados Unidos & 8612 & 11550 & 15347 & 17242 & 20553 & 20401 & 17280 & 18109 & 17026 & 14238 & 136.9 & -21.4 \\
\hline Unión Europea & 10824 & 16291 & 30712 & 22081 & 25276 & 26524 & 22982 & 20715 & 20157 & 15444 & 145.0 & -25.4 \\
\hline Japón & 3253 & 3671 & 4321 & 3759 & 5019 & 4955 & 3816 & 4117 & 3967 & 2688 & 52.3 & -34.7 \\
\hline Resto del Mundo & 11538 & 11749 & 6744 & 17843 & 19887 & 18021 & 15952 & 20479 & 20618 & 13837 & 56.2 & -32.4 \\
\hline \multicolumn{13}{|l|}{ Total extra } \\
\hline MERCOSUR & 36757 & 46373 & 61755 & 66097 & 76389 & 74811 & 64459 & 69046 & 66294 & 49397 & 103.5 & -28.4 \\
\hline Total general & 45843 & 58083 & 75750 & 83294 & 96880 & 95287 & 79885 & 86622 & 81625 & 59741 & 107.8 & -31.0 \\
\hline
\end{tabular}

a Excluye MERCosur y México.

b Incluye Bolivia, Colombia, Cuba, Ecuador y Venezuela.

Fuente: CEI con base en INDEC, SECEX, Secretaría Administrativa del MERCOSUR y Banco Central del Uruguay. 
integración orientada “desde dentro” (Marques-Pereira, 1998:6). Las preferencias comerciales tendieron a ser vistas por los brasileños y por varios de sus vecinos como definidas geográfica y relativamente locales, enfoque que en esos años se incorporó al MERCOSUR. No obstante, el modelo actual de sus flujos de comercio sugiere que los intereses comerciales de Brasil en el largo plazo pudieran extenderse más allá de las fronteras subregionales (Coes, 1996:84). ${ }^{9}$ Brasil podría ganar más que Argentina en términos de un acuerdo preferencial con Estados Unidos, además de que es el más afectado por el desvío de comercio en el mercado norteamericano como resultado del TLCAN (Bouzas, 1996:104). ${ }^{10}$ No obstante, hasta ahora, la posición oficial brasileña ha sido más escéptica ante la idea de negociar un acuerdo con Estados Unidos.

Es probable que una de las motivaciones de Brasil para acelerar la conformación del MERCOSUR estuviera vinculada al anuncio de formación del ALCA. Todavía más, en 1994 el gobierno brasileño propuso la creación de un Mercado Común de América del Sur ampliado, el cual promovería en una primera etapa la convergencia de acuerdos preferenciales de comercio en la subregión, como un paso previo para una convergencia hemisférica con el ALCA. No obstante, el retraso en la plurilateralización de las preferencias preexistentes ha diferido este objetivo para el futuro (Bouzas, 1996:105).

\section{La inversión extranjera directa y de cartera en el MERCOSUR}

En los países del MERCosur y en Chile el flujo neto de capitales privados en la segunda mitad de los ochenta alcanzó un promedio cercano a 3,000 millones de dólares, dando un salto a 21,000 millones de dólares entre 1990 y 1996, cuadruplicándose en 1998. Dentro de estos flujos la inversión extranjera directa (IED) alcanzó el primer lugar, con un promedio cercano a $50 \%$ de los flujos privados a mediados de los noventa y $70 \%$ hacia el año 2000, mientras que los ingresos oficiales se redujeron de $20 \%$ a principios de los ochenta a un porcentaje mínimo en el año 2000 (CEI, 2003:27).

Como puede observarse en el Cuadro 3, en Argentina el flujo neto de capitales privados (como porcentaje del PIB) se sextuplica en el periodo 1991-1995 con respecto al periodo 1986-1990 y se dobla en el de 1996-2000. En Brasil aumenta ocho veces en el

9 Esta opinión empata con la observación de Rodríguez (1997:150): "la vocación mostrada desde hace mucho tiempo por Brasil hacia un comercio más global, y más recientemente por Argentina, puede haber favorecido la apuesta del MERCosur por el regionalismo abierto que parece vislumbrarse en la actualidad". En años recientes Brasil envía alrededor de 30\% de sus exportaciones a la Unión Europea, entre 20 y $25 \%$ a Estados Unidos, porcentajes similares a los de América Latina y entre 15 y $20 \%$ a los países del Este de Asia.

10 El artículo de Bouzas publicado en el verano de 1996 analiza la eventualidad de que Estados Unidos hubiera decidido ampliar el TLCAN a toda Latinoamérica, el costo de exclusión resultaría más elevado para los países sudamericanos que para los de América Central y el Caribe, por lo que suscitaría posiblemente conductas defensivas para no quedar afuera, sobre todo por parte de las economías pequeñas. Es en este contexto que Brasil pudiera beneficiarse más que los otros miembros del MERcosur, tanto porque es la economía más grande de la subregión, como porque el TLCAN la había afectado más que a los otros miembros. La alternativa planteada por Bouzas en un contexto de regionalismo abierto, sería que el Pacto Andino y Chile convergieran con el Mercosur en un Área de Libre Comercio de Sudamérica, aunque esto no lo veía fácil de realizar. 
Cuadro 3

Flujo neto de capitales al MERcosur y Chile

(\% del pris promedio de cada periodo)

\begin{tabular}{|c|c|c|c|c|}
\hline País & 1980-1985 & $1986-1990$ & 1991-1995 & $1996-2000$ \\
\hline \multicolumn{5}{|l|}{ Argentina } \\
\hline Flujo neto privado & 3.0 & 0.6 & 3.5 & 7.8 \\
\hline Flujo neto privado IED & 0.4 & 0.8 & 1.6 & 4.0 \\
\hline Flujo neto privado de inv. acciones & 0.0 & 0.0 & 0.7 & 0.3 \\
\hline Flujo neto privado préstamos & 2.6 & -0.2 & 1.3 & 3.5 \\
\hline Flujo neto oficial & 0.1 & 0.4 & 0.5 & 0.2 \\
\hline \multicolumn{5}{|l|}{ Brasil } \\
\hline Flujo neto privado & 2.6 & 0.3 & 2.4 & 5.0 \\
\hline Flujo neto privado IED & 0.8 & 0.4 & 0.5 & 3.5 \\
\hline Flujo neto privado de inv. acciones & 0.0 & 0.0 & 0.7 & 0.4 \\
\hline Flujo neto privado préstamos & 1.8 & -0.1 & 1.3 & 1.2 \\
\hline Flujo neto oficial & 0.5 & 0.1 & -0.3 & 0.2 \\
\hline \multicolumn{5}{|l|}{ Chile } \\
\hline Flujo neto privado & 7.3 & 4.3 & 6.4 & 13.4 \\
\hline Flujo neto privado IED & 0.9 & 1.8 & 3.3 & 8.4 \\
\hline Flujo neto privado de inv. acciones & 0.0 & 0.4 & 0.8 & 0.2 \\
\hline Flujo neto privado préstamos & 6.4 & 2.1 & 2.4 & 4.7 \\
\hline Flujo neto oficial & 0.7 & 1.9 & -0.5 & -0.4 \\
\hline \multicolumn{5}{|l|}{ Paraguay } \\
\hline Flujo neto privado & 1.6 & 0.8 & 0.4 & 1.9 \\
\hline Flujo neto privado IED & 0.4 & 0.4 & 1.5 & 1.9 \\
\hline Flujo neto privado de inv. acciones & 0.0 & 0.0 & 0.0 & 0.0 \\
\hline Flujo neto privado préstamos & 1.3 & 0.4 & -1.1 & 0.1 \\
\hline Flujo neto oficial & 2.3 & 1.0 & 0.4 & 1.3 \\
\hline \multicolumn{5}{|l|}{ Uruguay } \\
\hline Flujo neto privado & 3.0 & 0.5 & 1.0 & s 1.9 \\
\hline Flujo neto privado IED & 0.6 & 0.4 & 0.5 & 0.8 \\
\hline Flujo neto privado de inv. acciones & 0.0 & 0.0 & 0.0 & 0.0 \\
\hline Flujo neto privado préstamos & 2.5 & 0.2 & 0.5 & 1.1 \\
\hline Flujo neto oficial & 0.3 & 1.0 & 0.9 & 0.9 \\
\hline
\end{tabular}

Fuente: Centro de Economía Internacional, con base en fMI, UNCTAD y CEPAL.

periodo 1991-1995 con respecto al periodo anterior y se duplica en el periodo 1996-2000, aunque los porcentajes son menores en Brasil que en Argentina. Chile, por su parte, muestra los porcentajes más elevados, mientras que Paraguay y Uruguay los más bajos.

Los flujos de inversion privada en cartera que recibe América Latina, tuvieron un fuerte incremento desde principios de los años noventa, en un ambiente de liberalización financiera promovida por los países desarrollados, acompañado de la intención por parte de las compañías que manejan fondos de jubilación, fondos de seguros así como fondos mutuos de inversión que operan en esos países, de obtener rendimientos más elevados en los países emergentes. 
Los países del MERCOSUR también recibieron importantes incrementos de inversión privada en cartera, la cual fue utilizada en buena parte para cubrir sus déficit externo y fiscal producidos por el modelo de estabilización. Así, de acuerdo con las estadísticas del Fondo Monetario Internacional, entre 1991 y 1998 Argentina recibió 95,680 millones de dólares y Brasil 132,552 millones en ese mismo periodo (CEI, 2003:29). Tales flujos se convirtieron en negativos para Argentina, porque entre 1999 y 2001 salieron capitales cercanos a 16,000 millones de dólares, mientras que en Brasil dichos flujos fueron todavía positivos, aunque muy bajos, tan sólo 8,129 millones en ese último periodo. Chile, a diferencia de Brasil y Argentina, recibió una cantidad mucho menor, la cual ascendió a 10,921 millones de dólares entre 1991 y 2001, habida cuenta de su economía más pequeña, pero también de que impuso un impuesto indirecto específico (un encaje no remunerado en el Banco Central) y un tiempo mínimo de permanencia a la entrada de capitales externos de corto plazo.

\section{La crisis financiera de Brasil y el impacto en su economía y en el MERCOSUR}

No cabe duda que los efectos del Plan Real sobre el ingreso y la incidencia de la pobreza un año después de su puesta en marcha fueron muy positivos, pero también es cierto que basados en una política de estabilización que lleva interconstruidos los desequilibrios fiscal y externo, encuentra sus límites en 1998 en vista de la fragilidad macroeconómica que provocó. Es evidente que el plan estabilizador permitió una mejoría inequívoca de renta que llevó a un buen número de personas (3.7 millones) a escapar de la línea de pobreza. La reducción de la proporción de pobres de $38 \%$ a $28 \%$ para el conjunto de seis regiones, a las que corresponden once millones de habitantes, evidencia un retorno al nivel de 1990, aunque al separar las metrópolis regionales se encuentran diferencias significativas (Rocha, 1996:19). ${ }^{11}$ No obstante, subsiste el hecho negativo de que a pesar de la reducción del número de pobres, estos tenían en 1996 un ingreso medio más bajo que el verificado en el primer mes del plan de estabilización.

Dentro del bloque hegemónico alrededor del gobierno de Cardoso, se impuso un fundamentalismo liberal sobre todo entre el lanzamiento del Plan Real y marzo de 1995, que buscó acabar con la era nacional-desarrollista de Getulio Vargas. No obstante que entre 1995 y 1998 se aplicaron medidas compensatorias, éstas se encontraban dentro de un desarrollismo liberal, los ejes de la política económica continuaron bajo el fundamentalismo liberal: “el ajuste fiscal 'definitivo' fue siempre postergado a lo largo del gobierno de Fernando Henrique Cardoso, la valorización cambiaria y los elevados intereses fueron convertidos en elementos permanentes de estabilización" (Sallum, 1999:38).

11 De acuerdo con Rocha, en Recife y Porto Alegre baja el porcentaje de pobres, pero aumenta el número absoluto de estos; en Salvador y São Paulo aumenta tanto la proporción de pobres como su número absoluto; mientras que tanto en Bello Horizonte como en Río de Janeiro baja tanto la proporción como el número absoluto de pobres. 
Por otra parte, el gobierno de Cardoso se caracterizó desde un principio por las difíciles relaciones con el movimiento sindical, sobre todo con la Central Única de Trabajadores (CUT) vinculada con Inácio Lula da Silva en las elecciones y su posterior oposición a los planes de privatización y reforma del Estado. También contribuyó a deteriorar dichas relaciones la denuncia de la Convención 158 de la Organización Internacional del Trabajo (огт), la cual trata de proteger a los trabajadores despedidos por las empresas. Lo anterior forma parte de una política más general de flexibilización numérica del mercado de trabajo con el objeto de disminuir sus costos y crear condiciones para la generación de empleos.

La flexibilización de la legislación laboral fue ganando fuerza durante el gobierno de Cardoso, y fue puesta en acción por medio de proyectos de ley y medidas provisorias. Estas últimas fueron una especie de decreto presidencial que en un plazo de treinta días podían convertirse en ley o, en caso de no hacerlo, podían ser vueltas a presentar, por lo que se convirtieron en un mecanismo legislativo del cual abusó el Poder Ejecutivo. Las medidas provisorias concentraron su atención en la flexibilización de las formas de contratación, en la jornada de trabajo y en la remuneración (Von Bulow, 1998:8).

Aun cuando la crisis brasileña fue catalizada por el contagio proveniente de la crisis rusa de agosto de 1998, fue la fragilidad de la economía generada por la política de estabilización la causa principal de la crisis. Esta política ancló el tipo de cambio al dólar, propició la sobrevaluación de la moneda, el desequilibrio fiscal y del sector externo, ${ }^{12}$ así como elevadas tasas de interés para atraer las inversiones externas que, a su vez, cubrirían dichos desequilibrios, pero tal política no se pudo sostener cuando sobrevinieron la salida de capitales y los ataques especulativos al real.

El plan de salvamento de 41.5 billones de dólares, con fondos del FMI, el Banco Mundial, el Banco Interamericano de Desarrollo (BID) y veinte gobiernos nucleados alrededor del Banco de Pagos Internacionales (BPI), tuvo como contrapartida un vasto programa de reducción de los déficit públicos. No obstante este primer programa no convenció a los inversionistas, ${ }^{13}$ por lo que después de las dificultades en el Congreso para aprobar las medidas propuestas y la decisión de Itamar Franco para decretar una moratoria de la deuda de su estado con el gobierno federal, la administración de Cardoso decidió dejar flotar el real en enero de 1999. El gobierno se comprometió frente al FMI a reducir la inflación en 5\% anual y a obtener un excedente primario del sector público entre 3 y $3.5 \%$ del PIB, contra $2.6 \%$ previsto en el plan inicial.

12 El déficit en cuenta corriente alcanzó una cifra récord de 34.6 billones en 1998, a pesar de que las autorida des afirmaban que no era motivo de preocupación en vista de que estaba financiado en más de 50\% por la inversión extranjera directa.

13 A pesar del plan de salvamento del FMi, la desconfianza de los inversionistas no desapareció en vista de que la estabilidad del real necesitaba de una baja inflación lo que a su vez presionaría para mantener la sobrevaluación del tipo de cambio. Además los intereses netos sobre la deuda externa tenían un elevado nivel en 1998 (11.5 billones de dólares) así como los dividendos pagados al extranjero de 6 billones de dólares hicieron dudar a los inversionistas de la bondad del plan de ajuste (Cordonnier, 1999:21). 


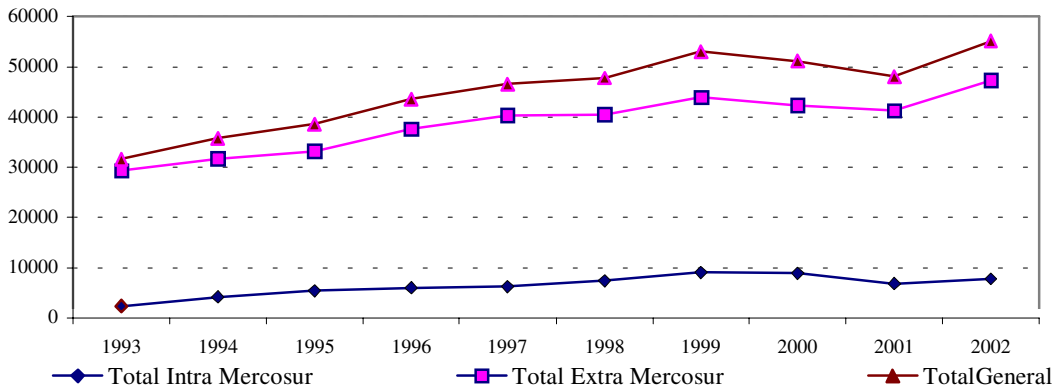

Gráfica 1. Exportaciones de Brasil 1991-2002 (millones de dólares).

Fuente: $\quad$ CEI con base en INDEC, SECEX.

El desempeño del sector externo brasileño que había tenido un incremento continuo desde 1991, tanto al interior como fuera del MERCOSUR, tendió a deteriorarse en 1998 y sobre todo en 1999, aunque logró recomponerse en términos globales entre 2000 y 2002 , pero no dentro del MERCOSUR, a pesar del relanzamiento de éste en el 2000. La estrepitosa caída de las exportaciones brasileñas intra MERCOSUR entre 2000 y 2002 fue compensada con las exportaciones extra MERCOSUR (véase Gráfica 1).

En términos porcentuales, las exportaciones intra MERCOSUR tendieron a la baja cerca de $2 \%$ en 1998 y $23.6 \%$ durante 1999, mientras que las extra MERCOSuR bajaron $3.8 \%$ y $2.4 \%$ respectivamente (véase Cuadro 4). En 2000 el intercambio con los países del MERCOSUR subió 14\%, pero en el 2001 bajó $17.7 \%$ y en 2002 se desplomó 48\%. En términos absolutos la caída de 4,422 millones de dólares intra MERCOSUR entre 2000 y 2002 fue compensada con el aumento de 9,698 millones en las exportaciones extra MERCOSUR en esos mismos años (véase Cuadro 4).

Sin embargo, la crisis económica y financiera de 1999 no trastocó el bloque hegemónico en el poder, aunque el ala desarrollista del bloque tomó cierta fuerza. ${ }^{14} \mathrm{Se}$ observa, pues, que el bloque neoliberal continuó hasta el final del mandato de Cardoso ${ }^{15}$ como el

14 De acuerdo con Eli Diniz (2000:98 100), el segundo mandato de Cardoso se inició con la profundización de las disidencias internas en la base de sustentación del gobierno, al contrario de lo que ocurrió durante su primer mandato, cuando la gobernabilidad fue asegurada por el éxito de la estabilización vía el Plan Real. Uno de los ejes del debate fue la controversia estabilización vs desarrollo que tuvo lugar en mayo de 1999. En el debate se delinearon claramente dos corrientes: de un lado la visión desarrollista, que abogaba por una mayor participación del Estado en el estímulo a los sectores productivos y en la reglamentación y fiscalización de la competencia con el capital extranjero, además de la necesidad de una política industrial capaz de fortalecer las empresas nacionales y garantizar la recuperación y el crecimiento. De otro lado, la visión neoliberal que reclamaba la prioridad de la austeridad fiscal, la continuidad de las privatizaciones, así como la profundización de la internacionalización de la economía, el libre mercado y la disminución de la intervención estatal.

15 La gestión del primer gobierno de Cardoso se aproximó a lo que se denomina fundamentalismo de mercado, y acabó penalizando fuertemente al sector productivo, obligado a ajustarse aceleradamente a los niveles mundiales de productividad, a ampliar el endeudamiento público y la fragilidad financiera de Brasil frente a las crisis financieras internacionales (mexicana, asiática y rusa). En el segundo gobierno se abandonó la política de ancla cambiaria y se estableció una rigurosa política fiscal, se obtuvo financiamiento del fMI en 2001 y 2002 que evitó la crisis cambiaria, y lenta e irregularmente el gobierno de Cardoso fue hacia una política liberal desarrollista. A pesar de los esfuerzos del gobierno el crecimiento económico fue muy bajo y el desempleo muy elevado, lo cual contribuyó a la victoria de Lula (Sallum y Kugelmas, 2003:7). 


\section{Cuadro 4}

Exportaciones de Brasil 1991-2002

(millones de dólares)

\begin{tabular}{|c|c|c|c|c|c|c|c|c|c|c|c|c|c|}
\hline $\begin{array}{c}\text { Países de } \\
\text { destino }\end{array}$ & 1991 & 1992 & 1993 & 1994 & 1995 & 1996 & 1997 & 1998 & 1999 & 2000 & 2001 & 2002 & $\begin{array}{l}\text { Var\% } \\
2000 \\
2002\end{array}$ \\
\hline Argentina & 1476 & 3040 & 3659 & 4136 & 4041 & 5170 & 6770 & 6748 & 5364 & 6233 & 5002 & 2342 & -62.4 \\
\hline Paraguay & 496 & 543 & 952 & 1054 & 1301 & 1325 & 1407 & 1249 & 744 & 832 & 720 & 558 & -32.9 \\
\hline Uruguay & 337 & 514 & 776 & 732 & 812 & 811 & 870 & 881 & 670 & 669 & 641 & 410 & -38.7 \\
\hline \multicolumn{14}{|l|}{$\begin{array}{l}\text { Total } \\
\text { intra }\end{array}$} \\
\hline MERCOSUR & 2309 & 4097 & 5387 & 5921 & 6154 & 7305 & 9047 & 8878 & 6778 & 7733 & 6364 & 3311 & -57.2 \\
\hline Com. Andina & 1194 & 1459 & 1645 & 1775 & 2115 & 1888 & 2530 & 2422 & 1752 & 2116 & 2529 & 2678 & 26.5 \\
\hline Chile & 677 & 924 & 1110 & 999 & 1210 & 1055 & 1197 & 1024 & 896 & 1246 & 1352 & 1461 & 17.2 \\
\hline TLCAN & 1847 & 8448 & 9294 & 10367 & 9640 & 10368 & 10688 & 11293 & 12256 & 15457 & 16613 & 18478 & 19.5 \\
\hline Canadá & 464 & 402 & 455 & 501 & 461 & 506 & 584 & 544 & 513 & 566 & 555 & 782 & 38.2 \\
\hline Estados Unidos & 624 & 6933 & 7843 & 8816 & 8683 & 9183 & 9276 & 9747 & 10675 & 13181 & 14190 & 15354 & 16.5 \\
\hline México & 758 & 1114 & 995 & 1050 & 496 & 679 & 828 & 1002 & 1068 & 1711 & 1868 & 2342 & 36.9 \\
\hline Unión Europea & 10096 & 10774 & 10190 & 12202 & 12912 & 12836 & 14514 & 14748 & 13736 & 14784 & 14865 & 15113 & 2.2 \\
\hline Resto Mundo & 15497 & 10092 & 10928 & 12281 & 14475 & 14295 & 15018 & 12774 & 12593 & 13748 & 16500 & 19321 & 20.5 \\
\hline \multicolumn{14}{|l|}{$\begin{array}{l}\text { Total } \\
\text { extra }\end{array}$} \\
\hline MERCOSUR & 29311 & 31696 & 33168 & 37624 & 40352 & 40442 & 43947 & 42262 & 41233 & 47353 & 51860 & 57051 & 9.6 \\
\hline $\begin{array}{l}\text { Total } \\
\text { general }\end{array}$ & 31620 & 35793 & 38555 & 43545 & 46506 & 47747 & 52994 & 51140 & 48011 & 55086 & 58224 & 60362 & 40.5 \\
\hline
\end{tabular}

Fuente: IED con base en SECEX.

principal tomador de decisiones y forjador de políticas públicas y en los primeros seis meses del gobierno de Luiz Inácio Lula da Silva, éste no ha escapado de la hegemonía política liberal (Sallum y Kugelmas, 2003:5). La administración de Lula ha profundizado la política económica del segundo gobierno de Cardoso, cuando menos en tres aspectos: 1) un ajuste fiscal más fuerte y una política monetaria más rígida; 2) se retoma el programa de reformas interrumpido por Cardoso: la reforma de la seguridad social (de carácter liberal), la reforma tributaria, la reforma laboral y la autonomía del Banco Central; 3) a pesar de que en la campaña electoral Lula y el Partido del Trabajo (РT) prometieron hacer de la política social el centro de sus acciones, ésta no se ha diferenciado de la del gobierno anterior. El programa Hambre Cero hasta ahora es poco más que un "slogan publicitario", dejando mucho que desear como realización concreta que anuncie con claridad una nueva fase de política social (Sallum y Kugelmas, 2003:10).

El gobierno de Lula enfrenta una situación paradójica: por una parte, sus esfuerzos para desactivar la oposición de empresarios y mercados financieros, expresada en el proceso electoral, lo llevaron a sobrerreaccionar por medio del aumento del superávit primario de finanzas públicas de $4.25 \%$, el mantenimiento de tasas de interés elevadas y la 
indiferencia frente a la sobrevaluación cambiaria, lo cual tiende a empeorar la situación económica y social. Por otra, aunque tuviera éxito y el Congreso aprobara las reformas estructurales, los grados de libertad que el desempeño de la economía le da al gobierno comienzan a generar tensiones sociales, las cuales serán difíciles de desactivar, a menos que haya un viraje hacia el populismo y la vinculación del gobierno con las masas. Lo peor sería que el viraje fuera hacia el autoritarismo (Sallum y Kugelmas, 2003:18-19).

\section{La crisis actual del MERCOSUR}

En vista de la caída en 1999 de cerca de 26\% del intercambio intra MERCosur, en diciembre de 2000 la XIX Reunión del Consejo Mercado Común adoptó una Declaración Presidencial, en la que oficialmente se anunció el relanzamiento del MERCosur. Se acordaron metas de inflación máxima de 5\% entre 2002 y 2005 y 4\% después de 2006, excepto para Paraguay, mientras que la deuda fiscal neta del sector público consolidado para el MERCOSUR, Chile y Bolivia no debía sobrepasar el 3\% del PIB en 2002. Hasta 2003 Brasil gozará un periodo de transición con una tasa máxima de 3.5\%. En 2005 se definirá la futura trayectoria, la cual será decreciente a partir del promedio para 2002-2004. También se aprobó una reducción del arancel externo común en $0.5 \%$ a partir de enero de 2001 y otro de $2.5 \%$ a ser discutido en la siguiente reunión del Consejo Mercado Común (BID-INTAL, 2002:24-25). Aun cuando se contemplaba alcanzar metas comunes de convergencia macroeconómica, las medidas fueron en su mayoría de carácter puntual y estuvieron más de acuerdo con los necesidades coyunturales de cada país (Bouzas, 2002).

A pesar de las medidas para el relanzamiento del MERCOSUR, en 2001 se presentó una caída de $11.6 \%$ en el intercambio entre sus miembros y un desplome de casi 34\% en 2002 (véase Cuadro 1). Las exportaciones de Argentina y Brasil dentro del MERCosur comenzaron a caer ligeramente en 1998, mientras que las de Paraguay sufrieron una inflexión a la baja desde 1997 y las de Uruguay bajaron a partir de 1999. Como se puede apreciar en la Gráfica 2, Brasil se muestra por arriba de Argentina en sus exportaciones entre 1991 y la mitad de 1994, superándolo, después, esta última desde ese año hasta 2002. Aunque con el relanzamiento del MERCosur los cuatro países tuvieron un repunte en el 2000, todavía por debajo de 1998, en el 2001 caen todos y en 2002 también, excepto Paraguay que tuvo un aumento insignificante (véase Gráfica 2).

En cuanto a las importaciones durante el periodo de vigencia del MERCOSUR, éste se abasteció $27.7 \%$ de la Unión Europea, 21.0\% de Estados Unidos, 31.4\% del resto del mundo, incluido Japón, y tan sólo $19.9 \%$ del propio MERCosur. Así, los países de éste siguen dependiendo, en buena parte, de las importaciones de bienes de capital e insumos de producción provenientes de Europa y Estados Unidos (véase Cuadro 2).

En términos agregados, las exportaciones totales del MERCOSUR tuvieron su punto más elevado en 1997 y su punto más bajo en 1999, creciendo de manera continua en los 


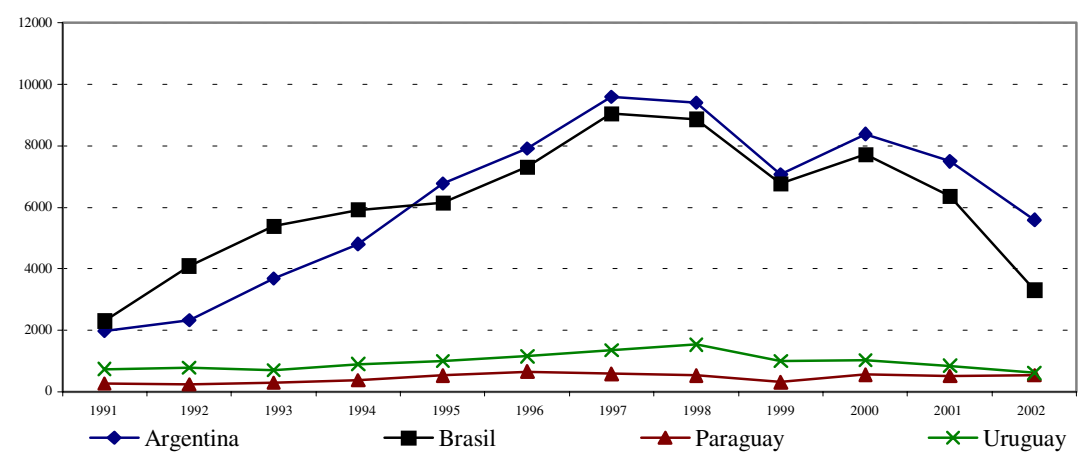

Gráfica 2. Exportaciones intra MERCOSUR 1991-2002 (millones de dólares).

Fuente: $\quad$ CEI con base en SECEX.

siguientes tres años. Este incremento se debió al aumento tan pronunciado de las exportaciones extra MERCOSUR entre 2000 y 2002, que fue capaz de absorber la baja de las exportaciones intra MERCOSUR.

La crisis del MERCOSUR tiene causas múltiples: por una parte, la evolución dispareja de sus dos miembros más grandes, sobre todo en relación con sus regímenes cambiarios, en vista de que Brasil mantuvo un tipo de cambio flotante desde 1999, mientras que Argentina mantuvo un tipo de cambio fijo hasta principios de 2002. En cuanto a esta última, su estancamiento desde 2000 y la crisis por la que todavía atraviesa, la indujeron a tomar una serie de medidas arancelarias y no arancelarias con el objeto de frenar sus importaciones y promover sus exportaciones; asimismo, Brasil aplicó varias medidas para administrar su comercio exterior. Lo anterior llevó a la dispersión arancelaria con respecto al AEC, lo que agravó las controversias comerciales entre ambos países (BID-INTAL, 2002:22). Por otra parte, y de manera fundamental, las diferencias en objetivos y estrategias entre Argentina y Brasil con respecto a su comercio exterior, así como la débil institucionalidad del esquema de integración, agudizaron la crisis del MERCosur. Veamos enseguida los argumentos más importantes acerca de las causas profundas de dicha crisis.

De acuerdo con Roberto Bouzas (2002:1-2), el MERCOSUR ha sido una experiencia exitosa de integración regional en términos de los estándares de los países en desarrollo, ya que ha contribuido a consolidar un ambiente de paz y democracia en el Cono Sur, así como al establecimiento de vínculos económicos más estrechos entre sus miembros. Sin embargo, el proceso de integración atraviesa en la actualidad por una profunda crisis que viene desde antes de las crisis económicas de sus miembros y que está vinculada a dos factores principales:

a) la gradual erosión de los objetivos comunes que impulsaron a los Estados parte a involucrarse en el proceso de integración regional, y $b$ ) la consecuente pérdida de foco y de capacidad para jerarquizar los problemas de política subyacente. La progresiva disolución de una visión de proyecto común y la consecuente pérdida de foco regional 
han transformado la agenda de negociación del MERCOSUR en una mera agregación de demandas nacionales.

Los miembros del MERCOSUR han visto frustradas las expectativas de proyección de sus intereses en el ámbito internacional, debido a las medidas unilaterales y discrecionalidad de su política interna que a menudo chocaban con los objetivos previstos para el MERCOSUR. Aunque este rasgo no fue exclusivo de Brasil, el mayor peso de su economía tuvo un impacto significativo en la relajación de los objetivos. La pérdida de foco del proceso integrador se expresó nítidamente en el frustrado relanzamiento de mediados del año 2000. En lugar de enfrentar la implementación del arancel externo común, la mejora en la coordinación y conducción de las negociaciones comerciales externas y el tratamiento de los impactos sectoriales provenientes de las turbulencias financieras, los miembros se enfrascaron en medidas puntuales que recogían demandas nacionales sin orden ni jerarquía de prioridades (Bouzas, 2002:4).

Otra interpretación en cuanto al impasse en el MERCOSUR (BID-INTAL, 2002), expresa que éste tiene, en primer lugar, una clara dimensión política que puede ser puesta en términos muy simples: el MERCOSUR no constituye ni para Brasil ni para Argentina la única estrategia posible de sus economías en el escenario internacional. Brasil dispone por lo menos de dos opciones: la primera consiste en buscar su inserción en el mundo en forma autónoma; la segunda, intentar promover una alianza estratégica con los países de su entorno, con el objetivo de consolidar su liderazgo en la región y garantizar una proyección del país en el escenario internacional. En esta segunda opción el MERCOSUR constituye una condición obligada pero no suficiente, ya que necesitaría de la adhesión de los demás países de América del Sur. Esto constituye una condicionante que tal vez explica la baja predisposición de Brasil para consolidar el núcleo y la clara preferencia por el ejercicio de un liderazgo de carácter más informal, de bajo costo y poco intensivo en reglas e instituciones. Argentina, por su parte, también contempla como proyecto estratégico alternativo al MERCOSUR la posibilidad de una inserción autónoma en la economía mundial, parecida a la de Chile, que trata de reducir costos de importación, promover la especialización en pocos sectores, explorar nichos de mercados que demanden uso intensivo de mano de obra calificada, firmar acuerdos de libre comercio con el mayor número de socios posible e intentar preservar un acceso preferencial al mercado brasileño.

La problemática actual del MERCOSUR tiene también una dimensión institucional, diagnóstico en el que muchos analistas están de acuerdo. La falta de instituciones y normas legales genera conflictos entre los miembros y dificulta la solución de problemas. Los dos miembros con economías más pequeñas, Paraguay y Uruguay, se quejan de que el predominio de normas laxas tiende a favorecer a los socios más grandes, en vista de su mayor capacidad para imponer soluciones. En cambio, Brasil se queja de que el actual sistema de decisión basado en el consenso concede a las economías menores un poder excesivo (BID-INTAL, 2002:ii). 
Bouzas (2002:5) critica las desviaciones e insuficiencias del proceso de integración mencionando que "un problema clave del MERCOSUR hoy no es que se trate de una unión aduanera 'incompleta', sino que es también una precaria área de libre comercio", sobre todo por la inestabilidad en las reglas de acceso a los mercados, la parálisis en el tratamiento de una serie de restricciones no tarifarias con efectos distorsionantes sobre el comercio y la ineficacia normativa.

El relanzamiento del MERCOSUR requiere del compromiso político de los gobiernos con el proceso de integración, concentrarse en un número pequeño de áreas, evitando la congestión de metas y objetivos. Tres son las áreas que deben privilegiarse de acuerdo con Bouzas (ibid.): a) cuestiones vinculadas con el acceso a mercados, $b$ ) la política comercial frente a terceros países, y $c$ ) mecanismos de creación de reglas e implementación de decisiones (ibid::7). En cuanto a esto último, BID y el INTAL (ibid.:iii) sugieren que para reforzar la estructura institucional del MERCOSUR se requiere: i) la creación de comités técnicos; ii) la institución de un Tribunal Arbitral dotado de mayor independencia y que conceda una cierta estabilidad a sus miembros; iii) el establecimiento de plazos o de procedimientos tipo fast track para la incorporación de normas a los ordenamientos jurídicos nacionales; y iv) la creación de un organismo común de defensa de la competencia.

\section{Brasil y el MERCOSUR frente al ALCA}

La Iniciativa de las Américas, lanzada por George Bush (padre) en Detroit en 1990, marca el comienzo de la propuesta de construcción del bloque de comercio más ambicioso del continente americano. Esta iniciativa contemplaba la creación de una zona continental de libre comercio, e incluía los temas de inversión extranjera y deuda externa, pero posteriormente este último tema se dejó de lado. La convocatoria de la Iniciativa de las Américas cristalizó en la Primera Cumbre de las Américas, la cual fue celebrada en diciembre de 1994 en Miami y asistieron 34 jefes de Estado. Su objetivo fue el establecimiento de un "Pacto para el desarrollo y la prosperidad: democracia, libre comercio y desarrollo sostenible en las Américas", el cual se concretará en un Área de Libre Comercio de las Américas (ALCA), cuya entrada en vigor está prevista para 2005. El Plan de Acción de la Cumbre contiene cuatro ejes temáticos:

I) La preservación y el fortalecimiento de la comunidad de democracias de las Américas. II) La promoción de la prosperidad mediante la integración económica y el libre comercio. III) La erradicación de la pobreza y la discriminación en nuestro hemisferio, y IV) La garantía del desarrollo sostenible y la conservación de nuestro medio ambiente para las generaciones futuras.

A imagen del Tratado de Libre Comercio de Norteamérica (TLCAN), el ALCA contempla una temática amplia que incluye: "las barreras arancelarias y no arancelarias que afecten el 
comercio de bienes y servicios, agricultura, subsidios, inversión, derechos de propiedad intelectual, compras de gobierno, barreras técnicas al comercio, salvaguardas, reglas de origen, derechos antidumping y compensatorios, normas y procedimientos sanitarios y fitosanitarios, solución de controversias y políticas de competencia" (Plan de Acción de la Primera Cumbre de las Américas).

Además, el Plan de acción de la Primera Cumbre incluyó una serie de materias consideradas como coadyuvantes al proceso de integración, entre las que se encuentran:

a) el desarrollo y liberación de los mercados de capital, la homologación de los reglamentos de mercados bancarios y bursátiles, así como la formación de una Comisión sobre Asuntos Financieros Hemisféricos; $b$ ) impulso a la construcción de infraestructura para agilizar el intercambio de bienes y servicios; $c$ ) la cooperación energética; $d$ ) el desarrollo de las telecomunicaciones y la infraestructura de la información; e) la cooperación en ciencia y tecnología, y $f$ ) impulso al turismo (Saavedra, 2003:34).

Sin embargo, la grandiosidad del objetivo y de los ejes de acción, sobre todo los de contenido social, no se han llevado a la práctica a través de medidas concretas, quedando, como apunta Gabriela Correa (2000:129), mayormente "en el limbo de las declaraciones". En cambio el objetivo central real — el libre comercio - es el que se ha estado instrumentando desde un principio. El proceso de construcción de éste se inició a partir de la formación de Grupos de Trabajo en las Reuniones Ministeriales de 1995 (Denver, Colorado), 1996 (Cartagena, Colombia) y 1997 (Bello Horizonte, Brasil), hasta completar 12 Grupos. ${ }^{16}$ En la Reunión Ministerial de 1998 (San José, Costa Rica), los 12 Grupos de Trabajo se convierten en 9 Grupos de Negociación, ${ }^{17}$ los cuales empezaron sus actividades a partir de la Segunda Cumbre de las Américas (Santiago de Chile, abril de 1998).

El proceso de negociación ha realizado avances, los cuales se plasmaron en un primer borrador del Acuerdo ALCA presentado en la sexta Reunión Ministerial celebrada en Buenos Aires en abril de 2001, y ratificada su publicación por la Tercera Cumbre de las Américas realizada en Québec en abril de 2001. El borrador revela una continuidad entre el TLCAN y el proyecto del ALCA en vista de que reproduce el modelo (Saavedra, 2003:57). Este autor muestra preocupación en relación con el artículo 16.5 por sus implicaciones neoproteccionistas, ya que: "establecería la posibilidad de restringir o prohibir la importación o exportación de bienes por razones de seguridad nacional, salud pública, preservación de la flora o fauna, del ambiente, sanitarias o fitosanitarias, normas, etiquetas,

16 En 1995 se crearon siete Grupos de Trabajo: acceso a mercados, procedimientos aduaneros y normas de origen, inversiones, normas y barreras técnicas, medidas sanitarias y fitosanitarias, medidas antidumping y compensatorias, y economías pequeñas. En 1996 se crearon cuatro grupos más: compras del sector público, propiedad intelectual, servicios, política de competencia. Finalmente, en 1997se creó el doceavo grupo para la solución de controversias.

17 Los Grupos de Negociación se han reunido en una misma sede, la cual es rotativa entre las ciudades de Miami, del 1o. de mayo de 1998 al 28 de febrero de 2001; ciudad de Panamá, del 1o. de marzo de 2001 al 28 de febrero de 2003, y Puebla, México, del 1o. de marzo de 2003 al 1o. de diciembre de 2004. 
reglamentos técnicos, compromisos internacionales, requerimientos de orden público o cualquier otras regulaciones".

Otras posibles implicaciones neoproteccionistas se observan en las reglas de origen, que otorgan un tratamiento tan amplio y puntual que podría derivar en el fortalecimiento de acciones proteccionistas, además de que favorecería a las economías de mayor desarrollo en vista de las dificultades que para administrar dichas reglas tendrían las economías pequeñas (ibid::58).

No obstante, una de las preocupaciones que reiteradamente surge, a pesar de las declaraciones de las Reuniones Ministeriales y de las Cumbres de las Américas de que se tomarán en cuenta las asimetrías entre las grandes y pequeñas economías, en el borrador tan sólo se matizan otorgando plazos mayores, diferenciados y de gracia para la desgravación de las economías pequeñas. Como apuntan tanto la CEPAL (1996), como otros autores (De la Reza, 1998; Escaith y Pérez, 1999; Saavedra, 2003), las economías latinoamericanas y del Caribe no tienen el grado homogéneo de preparación para participar en forma ventajosa en un acuerdo hemisférico, además, Estados Unidos pertenece ya a otros esquemas y está negociando nuevos acuerdos de integración, por lo que no está claro su nivel de compromiso con el ALCA.

El proceso de negociación dentro del ALCA ha seguido avanzando, ya que en julio de 2002 el presidente de Estados Unidos, George W. Bush promulgó la ley de Autoridad de Promoción Comercial (TPA por sus siglas en inglés), declarando "que le permitirá a su país concretar el acuerdo de libre comercio con Chile, buscar un acuerdo comercial con Centro América y avanzar hacia la creación del ALCA prevista para el año 2005" (Informe ALCA, núm. 1, agosto de 2002). Además, en la Séptima Reunión Ministerial celebrada el 1o. de noviembre de 2002 en Quito, Ecuador, se aprobó la publicación del segundo borrador del Acuerdo del ALCA. También las propuestas de reducción arancelaria para bienes, servicios, compras gubernamentales e inversiones quedó terminada en febrero de $2003,{ }^{18}$ los pedidos de mejoras de las ofertas de bienes serían terminadas en junio de 2003, mientras que las ofertas revisadas se presentarían a partir del 15 de julio de 2003 (Informe ALCA, núm. 4, noviembre de 2002).

18 Estados Unidos propuso eliminar los aranceles sobre $56 \%$ de los productos agrícolas a la fecha en que el ALCA entre en vigor, aunque podría tardar más de diez años para los más protegidos. A su vez, la oferta estadounidense prevé una desgravación para la Comunidad del Caribe (САRıсом) de 85\%, de 64\% para América Central, de $68 \%$ para la Comunidad Andina, mientras que para el mercosur sólo del 50\%. En cuanto a subsidios agrícolas, la negociación será llevada dentro de la Organización Mundial de Comercio (omc), por lo que Estados Unidos mantendrá los subsidios a sus agricultores. También ofrece eliminar todos los aranceles a productos textiles cinco años después de la firma del Acuerdo, y suprimiría inmediatamente los aranceles que gravan las importaciones de acero, madera, energía y equipos eléctricos entre otros, y en 2015 eliminaría las tasas de $65 \%$ de los bienes de consumo e industriales que entran al país. En cambio el mercosur presentó una oferta con junta de desgravamiento para bienes y productos que cubre $62 \%$ del comercio hemisférico, incluido el sector agrícola. En materia de servicios se hizo un preámbulo común pero las ofertas se elaboraron por separado. Argentina y Brasil harán la presentación en abril de 2003 y Paraguay y Uruguay ya hicieron una oferta inicial (Informe ALCA, núm. 7, marzo de 2003). 
La posición del MERCOSUR con relación al ALCA busca mantener la identidad del esquema y evitar ser diluido en el proceso de negociación de este último, por lo cual el MERCOSUR ha luchado por el reconocimiento como bloque unitario. Así, en la tercera Reunión Ministerial de Bello Horizonte en 1997, se acordó que el ALCA puede coexistir con los acuerdos bilaterales y subregionales existentes, pero que será un compromiso único comprensivo (single undertaking). Las principales divergencias entre el MERCOSUR y las posturas de Estados Unidos en el ALCA recaen sobre los temas de dumping y subsidios agrícolas, barreras fitosanitarias y defensa de la competencia, apertura de servicios y sobre la propiedad intelectual.

En la negociación del ALCA la visión de Brasil ha sido más autónoma que la de los otros países del MERCOSUR, sobre todo frente a la posición de Estados Unidos, tanto porque es el país pivote del esquema sudamericano en vista del mayor tamaño de su economía, como por su inserción en el comercio internacional al que dirige sus exportaciones en mayor proporción que dentro del propio MERCOSUR. En la primera semana de septiembre de 2002 se realizó en Brasil un plebiscito sobre la actitud que debería tomar frente al ALCA. Participaron más de 10 millones de personas y el 17 de septiembre los resultados fueron: 98.94\% de los votantes expresó que Brasil no debe firmar el tratado del ALCA, mientras que $95.94 \%$ indicó que Brasil no debe seguir en la mesa de negociaciones del ALCA.

En cuanto al reciente arribo a la presidencia de Brasil de Luiz Inácio Lula da Silva, en su primer pronunciamiento oficial, afirmó que buscará "profundizar la integración económica y comercial entre los países, rescatando el MERCOSUR como instrumento de integración nacional e implementando una negociación soberana frente a la propuesta del ALCA". Entre las organizaciones empresariales, sindicales y sociales involucradas en el ALCA existe una visión generalizada de que el futuro gobierno del PT no romperá con las negociaciones en curso, pero que será un negociador más duro y que exigirá, sobre todo de Estados Unidos, contrapartidas más consistentes en términos de apertura y disminución del proteccionismo. Los analistas que han seguido de cerca la trayectoria del PT, piensan que el gobierno seguirá negociando en el ALCA, pero con posiciones más firmes en relación con las reciprocidades respecto al acceso a los mercados. Es decir, en lo que se refiere al comercio exterior, el gobierno del PT posiblemente apostará a una liberalización que valga realmente para todos los países integrantes del acuerdo. Otra firme directriz de política exterior del PT se refiere al interés por construir un proceso de integración regional más cercano al modelo de la Unión Europea que al del ALCA (Informe del ALCA, núm. 4, noviembre de 2002:9).

\section{Reflexiones finales a manera de conclusión}

La estrategia de desarrollo económico de los regímenes militares (1964-1985) de Brasil apostó por una profundización del modelo de acumulación por sustitución de importacio- 
nes a marchas forzadas, tratando de pasar a una etapa superior, la de sustituir la compra externa de bienes de producción, para sobrepasar el agotamiento de la etapa de sustitución anterior y proveer tales insumos básicos para relanzar el crecimiento. Esta estrategia alcanzó sus límites en vista del carácter excluyente del modelo de crecimiento, además de que no se construyó la capacidad para crear un "núcleo endógeno de innovación y crecimiento" para hacer posible la reproducción menos dependiente del sistema productivo. ${ }^{19} \mathrm{Si}$ bien la coyuntura internacional de abundancia de financiamiento durante los años setenta, con tasas de interés negativas permitió continuar con el modelo de sustitución de importaciones, en la década de los ochenta con la sequía de capital de préstamo aplicada por los países desarrollados y la banca internacional, se hizo presente la crisis de la deuda externa.

Brasil se vio confrontado con la necesidad de llenar con sus propios recursos los desequilibrios provenientes de su inadecuada estructura de distribución del ingreso, desequilibrio que tomó la doble forma de un déficit democrático frente al mundo del trabajo, en el orden político de los militares, y de una subvaloración de las capacidades productivas del país en el orden económico. El empuje de la sociedad civil, desde mediados de los ochenta, privilegió la democratización política y el nuevo gobierno civil prefirió el ajuste externo y minimizó el ajuste interno. Así, de acuerdo con Jaime Marques-Pereira y Bruno Théret (2001:107), “el Brasil de la 'marcha forzada' se convirtió en el Brasil de la 'hiperinflación reptante', fruto de las transformaciones políticas democráticas combinadas con un conservadurismo económico" ${ }^{20}$

Desde finales de los setenta la política económica de los gobiernos militares hizo énfasis en la exportación de manufacturas, obteniendo cierto éxito, pero son los gobiernos civiles que los suceden, quienes tratan de formalizar relaciones económicas con Argentina para la formación de un mercado común en el futuro. Dada la proclividad de los gobiernos brasileños, hasta antes de Collor de Mello, al desarrollismo nacionalista, los acuerdos de integración económica precursores del MERCOSUR, podrían considerarse como una base para una sustitución de importaciones ampliada regionalmente, lo cual vincularía el dinamismo del mercado interno regional con la competitividad externa.

19 Por su parte, Celso Furtado (1999:59) apunta que: "la tela de fondo [de las crisis recurrentes brasileñas] es siempre la misma: la incapacidad de la clase dirigente para afrontar los problemas vinculados a la fuerte concentración del ingreso y la riqueza, que se traducen, de un lado en una tendencia excesiva al consumo y a la importación de bienes y, de otro, en una tasa de ahorro muy baja".

20 El régimen monetario brasileño es estructuralmente de una elevada inflación, lo cual refleja no sólo la incapa cidad del Estado de regular los conflictos distributivos en el seno de la sociedad (que surgen de la relación capital trabajo o de la competencia entre fracciones del capital), sino de aquello que ha hecho virtud de la necesidad, al privilegiar el crecimiento con relación a la estabilidad monetaria, política que se revierte en los gobiernos neoliberales. Hay que tomar en cuenta que hasta 1964 Brasil no disponía de un banco central y que después, al constituirse éste, tuvo que compartir sus prerrogativas de autoridad monetaria con el Banco de Brasil, apéndice del Tesoro y a la vez banco comercial y de desarrollo. Esta dualidad de autoridades mone tarias le permitió al Estado brasileño financiarse sin ceñirse a un control monetario (Marques Pereira y Théret, 2001:119). 
Sin embargo, el abandono del modelo de crecimiento por sustitución de importaciones en el gobierno de Collor y el afianzamiento de la política económica neoliberal en la primera administración de Cardoso, introducen una contradicción entre la necesidad de desarrollo económico y el privilegio a la estabilización de corte neoliberal (véase el compendio Tempo social de Sallum en la p. 5), lo cual a su vez influirá en la voluntad política de Brasil para salvaguardar los objetivos comunes en el MERCOSUR, sobre todo en la época de crisis en que se privilegian las coyunturas nacionales. Lo anterior pone en duda que el MERCOSUR pueda servir de base para el relanzamiento de un modelo de crecimiento que sustituya importaciones provenientes fuera de dicho esquema. Así, la crisis brasileña de 1999 y la devaluación del real sacuden las relaciones económicas con Argentina, a lo que se suma, poco después, la debacle económica y social de este último país que, a su vez, afecta sustantivamente el intercambio con Brasil.

La voluntad política de Argentina y Brasil expresada en 1990 de acelerar su integración y llegar a una unión aduanera en cinco años en lugar de diez, llevó al MERCosur a lograr un impulso extraordinario. En sus primeros ocho años de vida el MERCosur fue el principal beneficiario de la liberalización comercial y la inversión, y logró el intercambio entre 1993 y 1998 con lo cual logró en este último año 20,349 millones de dólares. Sin embargo, el debilitamiento de la voluntad política de los países integrantes del MERCosur, Argentina y Brasil principalmente, para avanzar en la administración del arancel externo común y en la institucionalización del esquema de integración, así como para resolver los problemas comunes producidos por los shocks externos y la caída en crisis de las dos economías, se reflejó en el desplome del intercambio intra MERCOSUR sobre todo en 2001 y 2002, después del fallido relanzamiento del año 2000.

Si bien en la segunda administración de Cardoso algunos integrantes destacados de su gobierno se pronunciaron por un desarrollismo, siempre dentro del orden neoliberal, de todas maneras predominó la hegemonía del bloque ortodoxo. El gobierno brasileño no tuvo la capacidad para promover una política de atención a la gestión del funcionamiento del MERCOSUR y privilegió, en los hechos, sus relaciones económicas con Europa y Estados Unidos, así como sus problemas macroeconómicos coyunturales. Por su parte, Argentina pareció darle más importancia a sus relaciones de intercambio con otros países fuera del MERCOSUR y tratar de resolver sus problemas domésticos. El comportamiento de estas dos economías refleja que sus estrategias frente al MERCOSUR han perdido peso frente al intercambio con otros esquemas y países. En lo que va de este nuevo siglo los vacíos que ha producido el desplome del intercambio al interior del MERCOSUR se han tratado de llenar a través de privilegiar sus relaciones comerciales y de inversión con la Unión Europea y con Estados Unidos, lo que dificulta aún más su recuperación.

Por otra parte, el proceso de negociación del ALCA también ha agregado más dificultades al funcionamiento del MERCOSUR. El comienzo de dicho proceso precipitó al MERCOSUR 
a privilegiar el libre comercio, en desmedro de la unión aduanera, sobre todo en lo relativo a la gestión del arancel externo común y las reglas de acceso a los mercados. El proceso de formación del ALCA puso en guardia al MERCOSUR cuya posición ha buscado mantener su identidad como bloque unitario y sus divergencias con el primero han sido principalmente sobre las medidas antidumping, las barreras no arancelarias, la propiedad intelectual, la apertura de servicios y, en especial, sobre los subsidios agrícolas de Estados Unidos. Además de las reticencias de las autoridades del MERCOSUR a la negociación del ALCA, las poblaciones de los países miembros del primero han manifestado un rechazo significativo al segundo. En Brasil se efectuó un plebiscito en el que más de diez millones de personas votaron de manera casi unánime $(98.9 \%)$ en contra de la firma del ALCA.

A la vista de los avances de la negociación del ALCA, con la presentación de dos borradores previos del Acuerdo, y la entrada a la última etapa de negociación en Puebla, México —bajo la presidencia de Brasil y Estados Unidos_- así como la autorización del Congreso de Estados Unidos al gobierno de Bush para el procedimiento del fast track (Autoridad de Promoción Comercial), hay probabilidad de que el ALCA entre en vigor en el año 2005.

La estrategia que más conviene al MERCOSUR frente al ALCA es la de reforzar el proceso de integración en la región sudamericana por varias razones. Tanto porque le daría una mejor posición de negociación frente a Estados Unidos dentro del ALCA, además que el nivel de intercambio alcanzado entre los miembros del MERCOSUR, ha dado por resultado una serie de interdependencias cuyo costo de oportunidad es elevado frente a una disolución del esquema. Tal parece que por detrás de los recientes acercamientos entre los gobiernos de los países miembros del MERCosur, sobre todo promovidos por Argentina y Brasil, está el convencimiento de la necesidad de reforzar el proceso de integración. Existe, por ejemplo, una propuesta del Ministerio de Relaciones Exteriores de Argentina (CEI: 2003) para la cooperación macroeconómica mediante la creación de un Área de Estabilidad Macroeconómica que eventualmente conduzca a una moneda única. También el MERCOSUR ha estado muy activo negociando acuerdos de integración con la Comunidad Andina de Naciones (CAN) y con el Mercado Común Centroamericano (MCCA), y ha avanzado en la negociación con la Unión Europea. ${ }^{21}$

Por su parte, Brasil ha mostrado un activo liderazgo dentro del MERCosur en lo referente al proceso de negociación del ALCA, a pesar de que le ha faltado un mayor compromiso político para impulsar al primero. Luiz Inácio Lula da Silva tiene una tarea difícil de cumplir, ya que de una parte el pueblo brasileño y la Central Única de Trabajadores se han manifestado casi unánimemente contra el ALCA, y por otra, las empresas transnacionales que operan en Brasil, el capital financiero internacional y Estados Unidos, presionan a

21 La Unión Europea adoptó en septiembre de 2002 un Programa Regional para el MERcosur durante el periodo 2002 2006, con un financiamiento de 48 millones de euros destinado a apoyar el perfeccionamiento del mercado interno de sus miembros, la construcción institucional del bloque y la participación de la sociedad civil en el proceso de integración. 
favor del acuerdo hemisférico. La opinión de analistas que han seguido de cerca la actuación de Lula y del PT estima que los dos son favorables a la entrada de Brasil al ALCA, pero a través de una negociación que salvaguarde los intereses de Brasil y los otros países del MERCosur. A pesar de que en Estados Unidos surgió la propuesta de un acuerdo de libre comercio con Brasil y los otros países del MERCOSUR, ${ }^{22}$ hasta ahora Lula ha sido consistente en sus declaraciones de apoyo al reforzamiento del MERCOSUR y de una negociación a fondo dentro del ALCA, aunque las políticas aplicadas en la economía brasileña han caminado por el lado neoliberal. ${ }^{23}$

\section{Bibliografía}

Agosin, Manuel R. y Ricardo Ffrench-Davis, "La liberalización comercial en América Latina", Revista de la CEPAL, núm. 50, agosto, Santiago de Chile, 1993.

BID-INTAL, Informe MERCOSUR, periodo 2000-2001, Washington, 2002.

Bouzas, Roberto, "El regionalismo en el hemisferio occidental: NAFTA, MERCOSUR y después", Desarrollo Económico, vol. 36, número especial, Buenos Aires, 1996.

— ,MERCOSUR: ¿Crisis económica o crisis de la integración?, Notas preparadas para el Grupo de Reflexión Prospectiva sobre el MERCOSUR, FLACSOUniversidad de San Andrés, 2002.

Cacciamali, María C., "Notas sobre o proceso de informalização no mercado de trabalho no contexto da globalização", São Paulo, FE-CAMPIPEA, 1998.

Cedro, Pablo, "Estados, actores sociales y agentes económicos: los procesos de integración regional. El caso del Mercosur", Primer Congreso Euro- peo de Latinoamericanistas, Salamanca, Universidad de Salamanca, 1996.

CEI, Cooperación macroeconómica en el MERCOSUR. Un análisis de la interdependencia y una propuesta de cooperación, Buenos Aires, Centro de Economía Internacional, 2003.

CEPAL, Barreras estadounidenses al comercio con América Latina y el Caribe, Santiago de Chile, 1996.

CEPAL, Los procesos de integración de los países de América Latina y el Caribe 2000-2001: avances, retrocesos y temas pendientes, Santiago de Chile, 2002 (Serie Comercio Internacional núm. 25).

CESI, Informe ALCA, Fundación Friederich Ebert Stiftung, Santiago, núm.1, agosto de 2002; núm. 2, septiembre de 2002; núm. 4, noviembre de 2002, y núm. 7, marzo de 2003.

Coes, Donald V., "Beyond northamerican free trade: options for Brazil”, en VIII Conferencia ANUIESprofmex, México y las Américas, México, ANUIES-Universidad de Guadalajara-PROFMEX, 1996.

22 El anuncio de una posible negociación económica entre Estados Unidos y el gobierno de Lula fue recibido con optimismo por algunos diplomáticos brasileños. El embajador de Uruguay en Ginebra, Carlos Pérez, considera que un acuerdo Brasil-Estados Unidos tiene sentido, en vista de que en América Latina Estados Unidos tienen acuerdos bilaterales con los esquemas de integración de la región y negocia uno con Chile, por lo que sólo falta rían los países del MERcosur. La propuesta de Estados Unidos de efectuar un acuerdo con el MERcosur siempre estuvo fundada en la necesidad de buscar un entendimiento con Brasil (Informe ALCA, núm. 2, septiembre 2002, p. 2).

23 La explicación que algunos partidarios de Lula dan a la orientación neoliberal de su política económica, es que tuvo que pactar con el FMI y los grandes empresarios brasileños y extranjeros, antes de acceder a la pre sidencia, y asegurarles que el servicio de la deuda externa seguiría cubriéndose y que se mantendría la política de estabilización económica, para desactivar su oposición, la salida de capitales, y recomponer la caí da del real frente al dólar. La política de negociación fuerte dentro del ALCA, que ha prometido Lula, tal parece que tiene más posibilidades de llevarla a cabo en vista del apoyo de los otros miembros del mercosur y la inconformidad del pueblo brasileño para formar parte del Acuerdo podría incorporarla como palanca de negociación. No obstante, esta inconformidad puede hacerlo perder legitimidad en caso de una negociación fallida dentro del ALCA. De cualquier manera, las oposiciones a las que se halla sujeta la política económica de Lula, no serán fáciles de ser remontadas. 
Cordonnier, Christophe, "La crise économique brésilienne”, Problèmes d'Amérique Latine, núm. 33, abril-junio, Paris, 1999.

Correa, Gabriela, "La propuesta hemisférica de integración económica: ALCA", Economía: Teoría y Práctica, Nueva Época, núm. 12, 2000, pp. 127-148.

Diniz, Eli, Globalização, reformas econômicas e elites empresariais, Río de Janeiro, Editora FGV, 2000.

Draibe, Sonia, Brasil: o sistema de proteção social e suas transformações recentes, Santiago de Chile, CEPAL/UNICAMP, 1992.

Escaith, Hubert y Esteban Pérez, "Los países pequeños y la integración hemisférica”, en G. de la Reza y R. Conde (coordinadores), Nuevas dimensiones de la integración, México, UAM/ Plaza y Valdés, 1999, pp. 175-207.

Furtado, Celso, "Punto de vista sobre la situación de Brasil", Problèmes d'Amérique Latine, núm. 33, Paris, abril-junio, 1999.

Lerman, Aída, "MERCosur: pasado y presente", en Germán de la Reza y Raúl Conde (coordinadores), Nuevas dimensiones de la integración. Del TLCAN al regionalismo hemisférico, México, UAM-Plaza y Valdéz, 1999, pp. 243-257.

—, Multilateralismo y regionalismo en América Latina, México, UAM-INTAM-M.A. Porrúa, 2002.

Marques-Pereira, Jaime, "Monnaie, légitimité politique et intégration regionale en Amérique Latine", Paris, mimeo, 1998.

_ médiations de la régulation et dynamiques macroéconomiques", en L'Année de la Régulation, núm. 5, Paris, 2001, pp. 105-143.

Reza, Germán de la, Liberación del comercio en el hemisferio occidental, México, IIEC-UNAM, 1998.

Rocha, Sonia, "Renda e pobreza: os impactos do Plano Real”, IPEA, 1996 (Texto para discusión, núm. 439).

Rodríguez, Gonzalo, "Anclas nominales y escenarios de coordinación macroeconómica en el MERCOSUR", Revista de la CEPAL, núm. 62, agosto, Santiago de Chile, 1997.

Saavedra, Francisco L., "El ALCA: ¿Libre comercio o consolidación neoproteccionista", tesis docto- ral, Universidad Autónoma MetropolitanaXochimilco, doctorado en Ciencias Sociales, Área de Relaciones Internacionales, México, octubre de 2002.

Salama, Pierre, Riqueza y pobreza en América Latina. La fragilidad de las nuevas políticas económicas, México, FCE-Universidad de Guadalajara, 1999.

Sallum, Brasilio, "Globalizacão e estratégia para o desenvolvimento: o Brasil nos anos 90”, ponencia, Seminario Internacional Estado e Sociedade: criando o futuro, Fundap, São Paulo, agosto, 1997.

_ desenvolvimentismo", Tempo Social, 11 (2), 1999, pp. 23-48.

—, y Eduardo Kugelmas, "Governo Lulacontinuidade, avanço ou regressao ?’, Departamentos de Sociología y Ciencia Política, Universidad de São Paulo, mimeo, 2003

Schvarzer, Jorge, "Le MERCOSUR. Du succès à la crise: le poids du Brésil", Problèmes d'Amérique Latine, número 33, abril-junio, Paris, 1999.

Secretaría Administrativa del MERCOSUR, Montevideo, 1998.

Soria, Víctor M., "Crecimiento económico y desarrollo de la seguridad social en Brasil y México", Economía: Teoría y Práctica, Nueva Época, núm. 5, México, 1995, pp. 39-60.

, "El mercado de trabajo en Brasil y México a la luz de la integración regional y la crisis financiera", Comercio Exterior, México, mayo de 2001, pp. 425-437.

, "Les réformes des systèmes de protection sociale au Brésil et au Mexique au cours des années 1990 dans le cadre du MERCosur et de l'Alena", en A. Musset y V. M. Soria (coordinadores), Alena- MERcosur, Enjeux et limites de l'intégration américaine, Paris, INTAM-IHEAL, 2001, pp. 71-97.

Valenzuela, José C., ¿Qué es un patrón de acumulación?, México, FE-UNAM, 1990.

Von Bülow, Marisa, "Reforma trabalhista em um contexto de integracão hemisférica: o caso do Brasil", ponencia, Congreso de Latin American Studies Association, Chicago, 24-26 de septiembre, 1998. 